Review

\title{
Nanocomposites for food packaging applications
}

\author{
Henriette M.C. de Azeredo* \\ Embrapa Tropical Agroindustry, R. Dra. Sara Mesquita, 2270, Fortaleza, CE, CEP 60511-110, Brazil
}

\section{A R T I C L E I N F O}

\section{Article history:}

Received 3 January 2009

Accepted 30 March 2009

\section{Keywords:}

Nanotechnology

Biodegradable polymers

Whiskers

Nanofillers

\begin{abstract}
A B S T R A C T
Most materials currently used for food packaging are non-degradable, generating environmental problems. Several biopolymers have been exploited to develop materials for eco-friendly food packaging. However, the use of biopolymers has been limited because of their usually poor mechanical and barrier properties, which may be improved by adding reinforcing compounds (fillers), forming composites. Most reinforced materials present poor matrix-filler interactions, which tend to improve with decreasing filler dimensions. The use of fillers with at least one nanoscale dimension (nanoparticles) produces nanocomposites. Nanoparticles have proportionally larger surface area than their microscale counterparts, which favors the filler-matrix interactions and the performance of the resulting material. Besides nanoreinforcements, nanoparticles can have other functions when added to a polymer, such as antimicrobial activity, enzyme immobilization, biosensing, etc. The main kinds of nanoparticles which have been studied for use in food packaging systems are overviewed, as well as their effects and applications.
\end{abstract}

(c) 2009 Elsevier Ltd. All rights reserved.

\section{Contents}

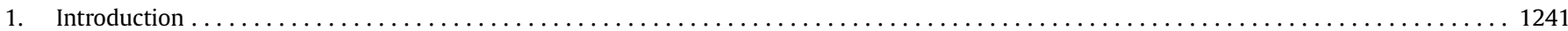

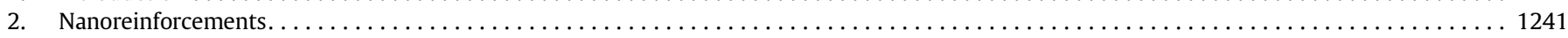

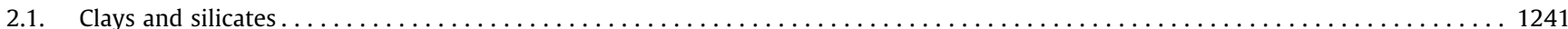

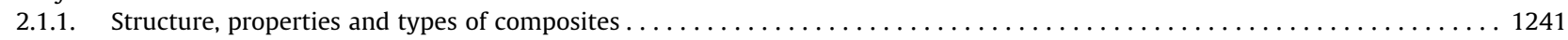

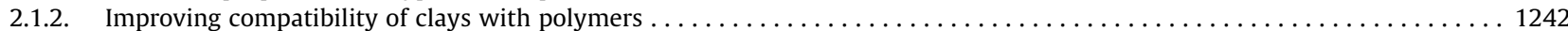

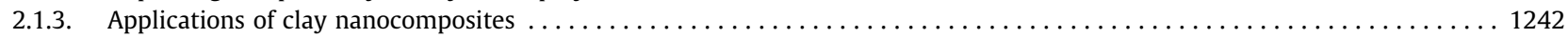

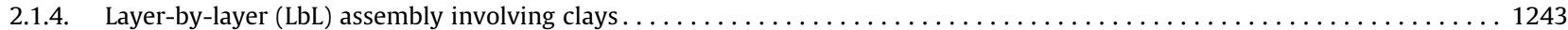

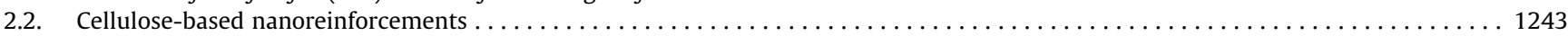

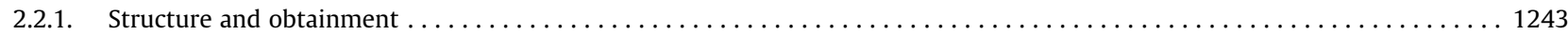

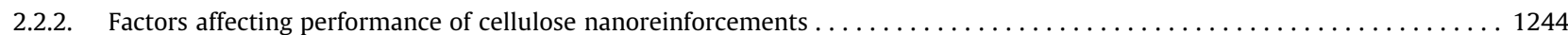

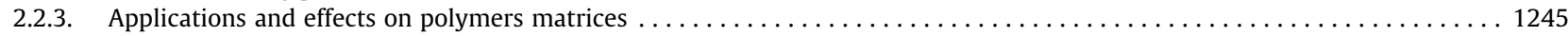

2.2.4. Improving compatibility between cellulose nanofibers and hydrophobic matrices. . . . . . . . . . . . . . . . . . .

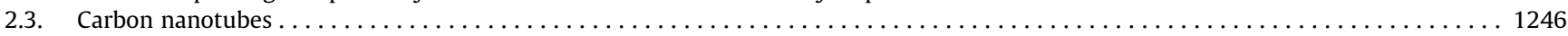

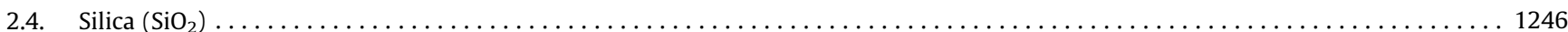

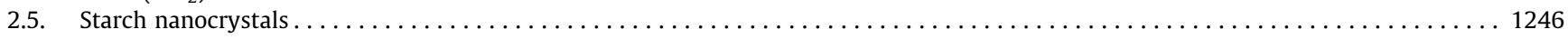

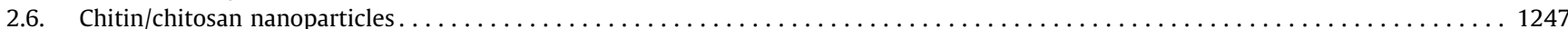

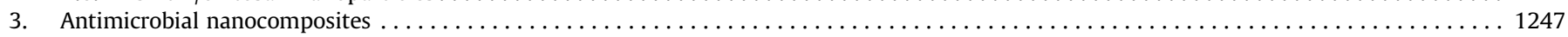

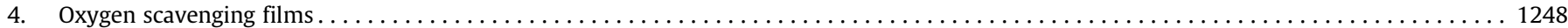

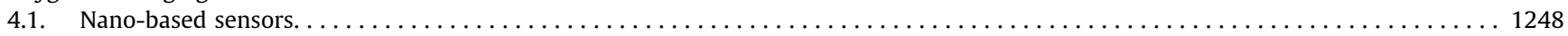

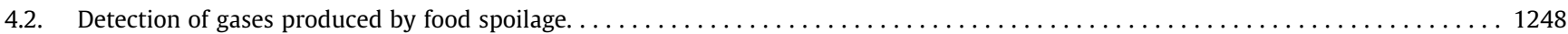

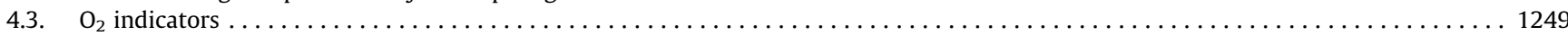

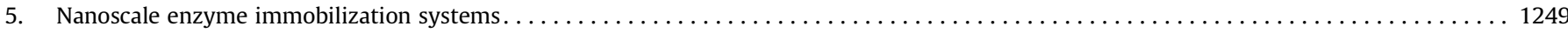

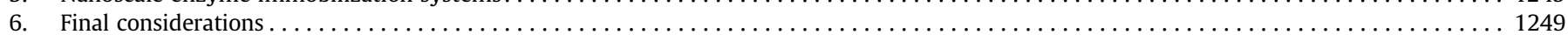

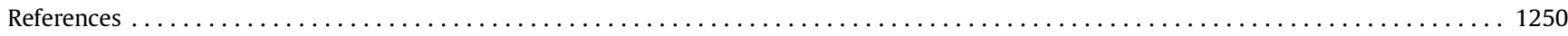

\footnotetext{
* Tel.: +55 85 32991850; fax: +55 8532991833.

E-mail address: ette@cnpat.embrapa.br
} 


\section{Introduction}

"Nano-" denotes nanometer $\left(10^{-9} \mathrm{~m}\right)$. The concept of nanotechnology was introduced by Richard Feynman in 1959 at a meeting of the American Physical Society (Khademhosseini \& Langer, 2006). Since then, nanotechnology has developed into a multidisciplinary field of applied science and technology. Nanotechnology is the ability to work on a scale of about $1-100 \mathrm{~nm}$ in order to understand, create, characterize and use material structures, devices and systems with new properties derived from their nanostructures (Roco, 2003). Because of their size, nanoparticles have proportionally larger surface area and consequently more surface atoms than their microscale counterpart. In the nanoscale range, materials may present different electronic properties, which in turn affects its optical, catalytic and other reactive properties (Boccuni, Rondinone, Petyx, \& Iavicoli, 2008; Kahn, 2006).

All biological and man-made systems have the first level of organization at the nanoscale. By using nanotechnology techniques, it is possible to assemble molecules into objects, along several length scales, and to disassemble objects into molecules, as nature already does (Roco, 2003).

Two building strategies are currently used in nanotechnology: a "top-down" approach and the "bottom-up" approach. The commercial scale production of nanomaterials currently involves basically the "top-down" approach, in which nanometric structures are obtained by size reduction of bulk materials, by using milling, nanolithography, or precision engineering. Size usually relates to functionality of food materials, smaller sizes meaning a bigger surface area, desirable for several purposes. The newer "bottom-up" approach, on the other hand, allows nanostructures to be built from individual atoms or molecules capable of self-assembling (Föster \& Konrad, 2003; Moraru et al., 2003). Self-assembly relies on balancing attraction and repulsion forces between a pair of molecules as building blocks to form more functional supramolecular structures (Sanguansri \& Augustin, 2006).

Nowadays, most materials used for food packaging are practically undegradable, representing a serious global environmental problem. New bio-based materials have been exploited to develop edible and biodegradable films as a big effort to extend shelf life and improve quality of food while reducing packaging waste (Tharanathan, 2003). However, the use of edible and biodegradable polymers has been limited because of problems related to performance (such as brittleness, poor gas and moisture barrier), processing (such as low heat distortion temperature), and cost. Starch, as an example, has received considerable attention as a biodegradable thermoplastic polymer. However, it has a poor performance by itself because of its water sensitivity and limited mechanical properties (Vaidya \& Bhattacharya, 1994) with high brittleness, which is related to the anarchical growth of amylose crystals with time (Dufresne \& Vignon, 1998). The application of nanotechnology to these polymers may open new possibilities for improving not only the properties but also the cost-price-efficiency (Sorrentino, Gorrasi, \& Vittoria, 2007).

Several composites have been developed by adding reinforcing compounds to polymers to enhance their thermal, mechanical and barrier properties. Most of these reinforced materials present poor interactions at the interface of both components. Macroscopic reinforcing components usually contain defects, which become less important as the particles of the reinforcing component are smaller (Ludueña, Alvarez, \& Vasquez, 2007).

Polymer composites are mixtures of polymers with inorganic or organic fillers with certain geometries (fibers, flakes, spheres, particulates). The use of fillers which have at least one dimension in the nanometric range (nanoparticles) produces polymer nanocomposites (Alexandre \& Dubois, 2000). Three types of fillers can be distinguished, depending on how many dimensions are in the nanometric range. Isodimensional nanoparticles, such as spherical silica nanoparticles or semiconductor nanoclusters, have three nanometric dimensions. Nanotubes or whiskers are elongated structures in which two dimensions are in the nanometer scale and the third is larger. When only one dimension is in the nanometer range, the composites are known as polymer-layered crystal nanocomposites, almost exclusively obtained by the intercalation of the polymer (or a monomer subsequently polymerized) inside the galleries of layered host crystals (Alexandre \& Dubois, 2000).

A uniform dispersion of nanoparticles leads to a very large matrix/filler interfacial area, which changes the molecular mobility, the relaxation behavior and the consequent thermal and mechanical properties of the material. Fillers with a high ratio of the largest to the smallest dimension (i.e., aspect ratio) are particularly interesting because of their high specific surface area, providing better reinforcing effects (Azizi Samir, Alloin, \& Dufresne, 2005; Dalmas, Cavaillé, Gauthier, Chazeau, \& Dendievel, 2007; Dubief, Samain, \& Dufresne, 1999). In addition to the effects of the nanoreinforcements themselves, an interphase region of altered mobility surrounding each nanoparticle is induced by well dispersed nanoparticles, resulting in a percolating interphase network in the composite and playing an important role in improving the nanocomposite properties (Qiao \& Brinson, 2009). According to Jordan, Jacob, Tannenbaum, Sharaf, and Jasiuk (2005), for a constant filler content, a reduction in particle size increases the number of filler particles, bringing them closer to one another; thus, the interface layers from adjacent particles overlap, altering the bulk properties significantly.

Besides reinforcing nanoparticles, whose main role is to improve mechanical and barrier properties of the packaging materials, there are several types of nanostructures responsible for other functions, sometimes providing active or "smart" properties to the packaging system such as antimicrobial activity, enzyme immobilization, biosensing, etc. The most studied nanoparticles will be presented according to their primary functions/applications in food packaging systems. Some particles can have multiple applications, and sometimes the applications can overlap, such as some immobilized enzymes which can act as antimicrobial components, oxygen scavengers and/or biosensors.

\section{Nanoreinforcements}

\subsection{Clays and silicates}

\subsubsection{Structure, properties and types of composites}

Although several nanoparticles have been recognized as possible additives to enhance polymer performance, the packaging

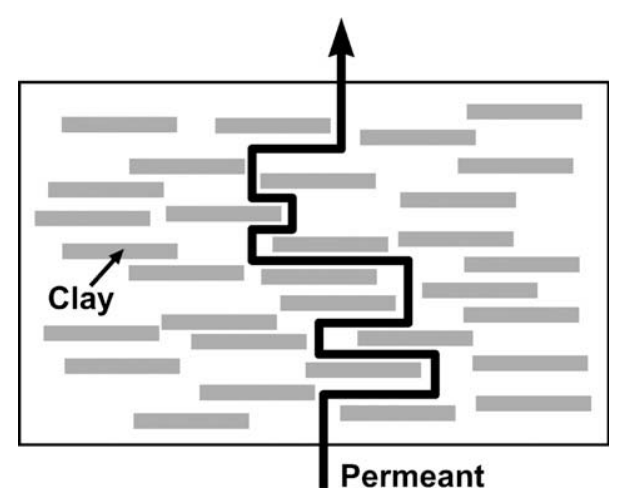

Fig. 1. Tortuous path of a permeant in a clay nanocomposite. (Adapted from Adame \& Beall, 2009) 
industry has focused its attention mainly on layered inorganic solids like clays and silicates, due to their availability, low cost, significant enhancements and relative simple processability. The concept of polymer-clay nanocomposites (PCN) was developed in the late 1980 s, and firstly commercialized by Toyota (Collister, 2002), but only since the late 1990s researches have been published on development of PCN for food packaging (Ray, Easteal, Quek, \& Chen, 2006). The layered silicates commonly used in nanocomposites consist of two-dimensional layers, which are $1 \mathrm{~nm}$ thick and several microns long depending on the particular silicate. Its presence in polymer formulations increases the tortuosity of the diffusive path for a penetrant molecule (Fig. 1), providing excellent barrier properties (Bharadwaj et al., 2002; Cabedo, Giménez, Lagaron, Gavara, \& Saura, 2004; Mirzadeh \& Kokabi, 2007).

In contrast with the tactoid structure predominating in microcomposites (conventional composites), in which the polymer and the clay tactoids remain immiscible, resulting in agglomeration of the clay in the matrix and poor macroscopic properties of the material (Alexandre et al., 2009; Ludueña et al., 2007), the interaction between layered silicates and polymer chains may produce two types of ideal nanoscale composites (Fig. 2). The intercalated nanocomposites result from the penetration of polymers chains into the interlayer region of the clay, resulting in an ordered multilayer structure with alternating polymer/inorganic layers at a repeated distance of a few nanometers (Weiss, Takhistov, \& McClements, 2006). The exfoliated nanocomposites involve extensive polymer penetration, with the clay layers delaminated and randomly dispersed in the polymer matrix (Ludueña et al., 2007). Exfoliated nanocomposites have been reported to exhibit the best properties due to the optimal interaction between clay and polymer (Adame \& Beall, 2009; Alexandre et al., 2009; Osman, Rupp, \& Suter, 2005).

The most widely studied type of clay fillers is montmorillonite (MMT), a hydrated alumina-silicate layered clay consisting of an edge-shared octahedral sheet of aluminum hydroxide between two silica tetrahedral layers (Weiss et al., 2006). The imbalance of the surface negative charges is compensated by exchangeable cations (typically $\mathrm{Na}^{+}$and $\mathrm{Ca}^{2+}$ ). The parallel layers are linked together by weak electrostatic forces (Tan, Zhang, Szeto, \& Liao, 2008). This type of clay is characterized by a moderate negative surface charge (cation exchange capacity, CEC), which is an important factor to define the equilibrium layer spacing. The charge of the layer is not locally constant as it varies from layer to layer and must rather be considered as an average value over the whole

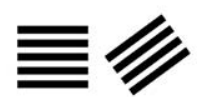

Layered silicate

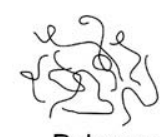

Polymer

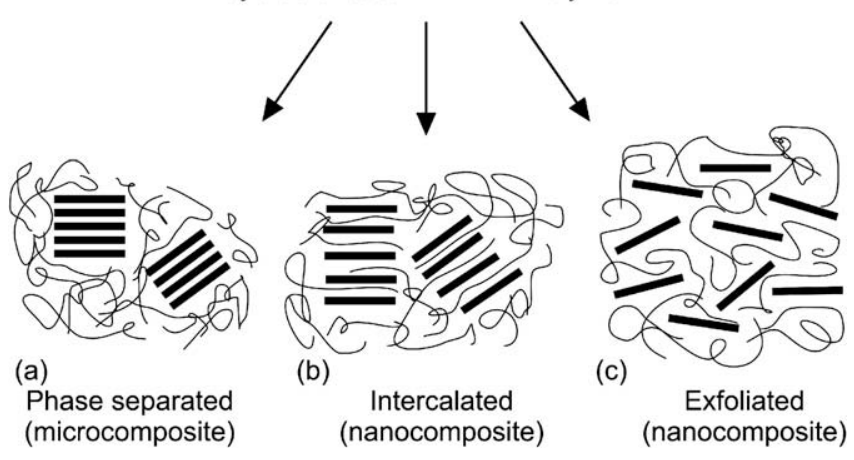

Fig. 2. Types of composite derived from interaction between clays and polymers: (a) phase-separated microcomposite; (b) intercalated nanocomposite and (c) exfoliated nanocomposite. (Alexandre \& Dubois, 2000). crystal (Alexandre \& Dubois, 2000). MMT is an effective reinforcement filler, due to its high surface area and large aspect ratio (501000) (Uyama et al., 2003).

\subsubsection{Improving compatibility of clays with polymers}

The homogeneous dispersion of most clays in organic polymers is not easy due to the hydrophilicity of its surface (Kim, Lim, Park, \& Lee, 2003). Organoclays, products from interactions between clay minerals and organic compounds, have found an important application in polymer nanocomposites. A proper organophilization is a key step for successful exfoliation of clay particles in most polymeric matrices. The organophilization reduces the energy of the clay and improves its compatibility with organic polymers (Paiva, Morales, \& Díaz, 2008). Organoclays are cheaper than most other nanomaterials, since they come from readily available natural sources, and are produced in existing, full-scale production facilities (Markarian, 2005). Organomontmorillonite (oMMT) have been produced, for example, by exchanging inorganic cations of MMT with organic ammonium ions, improving compatibility of MMT with organic polymers (Osman, Ploetze, \& Suter, 2003; Paul et al., 2003), leading to a more regular organization of the layers in the structures, and decreasing the water uptake by the nanocomposite (Picard, Gauthier, Gérard, \& Espuche, 2007).

Surfactants can also be used to improve the dispersibility of the clay. Osman et al. (2005) used amphiphilic block and random polyethylene copolymers as surfactants to improve dispersion of oMMT in a polyethylene (PE) matrix; the surfactants were able to increase spacing between clay layers ( $d$-spacing) to different extents, depending on the number of polar units in the copolymer molecule.

Park, Liang, Mohanty, Misra, and Drzal (2004) used maleic anhydride grafted cellulose acetate butyrate (CAB-g-MA) as compatibilizer for cellulose acetate nanocomposites with an oMMT. Nanocomposites with compatibilizer showed better exfoliated structure and better mechanical properties than the counterpart without compatibilizer.

\subsubsection{Applications of clay nanocomposites}

Since clay layers constitute a barrier to gases and water, forcing them to follow a tortuous path, the introduction of nanoclays into polymer biostructures has been shown to greatly improve barrier properties (Adame \& Beall, 2009), minimizing one of the main limitations of biopolymer films. Indeed, many studies have reported the effectiveness of nanoclays in decreasing oxygen (Bharadwaj et al., 2002; Cabedo et al., 2004; Cava, Giménez, Gavara, \& Lagaron, 2006; Koh et al., 2008; Lagaron et al., 2005; Lotti et al., 2008; Mangiacapra, Gorrasi, Sorrentino, \& Vittoria, 2006; Petersson \& Oksman, 2006a) and water vapor permeabilities (Bharadwaj, 2001; Jawahar \& Balasubramanian, 2006; Lotti et al., 2008; Mangiacapra et al., 2006).

The most widely known theories to explain the improved barrier properties of polymer-clay nanocomposites are based on a theory developed by Nielsen (1967), which focuses on a tortuous path around the clay plates, forcing the gas permeant to travel a longer path to diffuse through the film. The increase in path length is a function of the high aspect ratio of the clay filler and the volume\% of the filler in the composite. Nielsen's model predicts permeability of systems at clay loading rates of less than $1 \%$, but experimental data deviates significantly from predicted values at higher loading rates and more extensively in certain polymers. According to Bharadwaj (2001), increased length of silicate sheets enhance the barrier properties, because of the increased tortuosity.

Many deviations can be explained by factors such as poor clay orientation or less than complete exfoliation. However, even those factors cannot explain many published experimental observations that reported much lower permeabilities than predicted (Adame \& 
Beall, 2009). Beall (2000) proposed a new model to predict permeability of polymer nanocomposites, focused on the polymer-clay interface as the governing factor in addition to the tortuous path. This model provides a correction factor applicable to Nielsen's model. It defines three regions around clay plates: the surface modifier region, the constrained polymer region, and the unconstrained polymer region. The surface modifier region (1-2 nm) binds the clay with the polymer; it is assumed to be small enough to have little effect on the permeability of the composite. The unconstrained polymer region is not affected significantly by the clay, its properties being that of the bulk polymer. The constrained polymer region, less well defined and indirectly confirmed, is in direct contact with the surface modifier and may extend 50-100 nm from the clay surface as a function of polymer interaction parameters; it is assumed to have a lower free volume and therefore a lower diffusion coefficient than that of the bulk polymer. Since the main effect of the constrained region is to lower free volume, and this effect is not significant in crystalline regions, the constrained region of semicrystalline polymers does not significantly affect permeability unless the crystallinity is decreased. Indeed, most of the large deviations from the simple tortuous path model involve amorphous polymers (Adame \& Beall, 2009).

Clays have been also reported to improve the mechanical strength of biopolymers, making their use feasible (Weiss et al., 2006). Park, Lee, Park, Cho, and Ha (2003) generated thermoplastic starch (TPS)/clay nanocomposites with improved mechanical properties and decreased water vapor permeability by using only $5 \%$ (w/w) of clays. Reports by Dean, Yu, and Wu (2007) indicate that optimum levels of both plasticizer and nanoclay exist for each clay to produce a gelatinized starch film with the highest exfoliation and best improvement in mechanical properties, and those optimum levels have some dependency on the CEC of the clay. Petersson and Oksman (2006a) reported that bentonite was able to improve strength and modulus of a polylactic acid (PLA) matrix, but it drastically decreased elongation of the material. Similar results were reported by Lotti et al. (2008) for low-density polyethylene (LDPE) treated with an organoclay, and also by Xu, Ren, and Hanna (2006) for chitosan films with MMT. On the other hand, Marras, Kladi, Tsivintzelis, Zuburtikudis, and Panayiotou (2008) reported that the elongation of poly ( $\varepsilon$-caprolactone) $(\mathrm{PCL})$ was not impaired by MMT. Other authors observed improved mechanical properties of several polymers by addition of nanoclays (Avella et al., 2005; Chen \& Evans, 2005; Cyras, Manfredi, Ton-That, \& Vázquez, 2008; Jawahar \& Balasubramanian, 2006; Mangiacapra et al., 2006; Russo, Nicolais, Di Maio, Montesano, \& Incarnato, 2007; Yu, Lin, Yeh, \& Lin, 2003).

Other benefits have been reported on the performance of a diversity of polymers as resulting from using clay nanoparticles, including increased glass transition (Cabedo et al., 2004; Petersson \& Oksman, 2006a; Yu et al., 2003) and thermal degradation temperatures (Bertini, Canetti, Audisio, Costa, \& Falqui, 2006; Cabedo et al., 2004; Cyras et al., 2008; Paul et al., 2003; Yu et al., 2003). As minor disadvantages of nanoclays on polymers, $\mathrm{Yu}$ et al. (2003) have described decreased transparency.

Some companies in the USA, such as Nanocor Inc. (Arlington Heights, IL) and Southern Clay Products, Inc. (Gonzales, TX) have been working on incorporation of MMT in nanocomposite production, making plastics lighter, stronger, more heat-resistant and with improved barrier against gases, moisture and volatiles (Moraru et al., 2003). Some industries have incorporated clays in nylon6 , which is fluid and easily penetrates small spaces between layers. When extruded, platelets orient themselves parallel to the surface, improving barrier properties (Brody, 2007). Nylon-6 nanocomposites can achieve oxygen transmission rates almost four times lower than that of neat nylon-6 (Brody, 2003). Nanocor and Mitsubishi Gas Chemical (New York, NY) have developed Imperm $^{\circledR}$, a nano- composite nylon MXD6 with much improved barrier properties, to be used in films and PET bottles (Brody, 2006, 2007). The nanocomposite material can be used as an oxygen barrier layer in the extrusion manufacturing of bottles for fruit juices, dairy foods, beer and carbonated drinks, or as nanocomposite layers in multilayer films to enhance the shelf life of a variety of foods such as processed meats, cheese, confectionery, cereals, and boil-in-bag foods (Brody, 2007; Moraru et al., 2003).

According to Brody (2006), the US Army Natick Soldier Center (Natick, MA), the core site of military ration research, has been searching for alternatives to laminations (particularly aluminum foil) to enhance shelf life of room-temperature shelf-stable foods, to reduce solid waste from package materials, and to allow fast reheating in microwave ovens. One direction is to incorporate nanoclay into plastic matrices to improve barrier properties, thermal resistance, and mechanical strength. Natick research has focused on formulating PE, PET, and ethylene vinyl alcohol (EVOH) with $1-5 \%$ nanoclay platelet weight, the clay platelets being properly dispersed to maximize orientation, a key variable in producing the tortuous pathways. Results have indicated increases of $80 \%$ in thermal resistance and $100 \%$ in mechanical strength. On the other hand, EVOH was still sensitive to water vapor even after combined with nanoclays.

\subsubsection{Layer-by-layer ( $L b L)$ assembly involving clays}

Layer-by-layer (LbL) self-assembly is a method by which a multilayer coating/film of nanometer-thick layers can be made by sequential adsorption of oppositely charged polyelectrolytes on a solid support (Rudra, Dave, \& Haynie, 2006).

Jang, Rawson, and Grunlan (2008) made a multilayer film by depositing intercalating layers of anionic sodium MMT and cationic polyacrylamide on a PET substrate. Oxygen transmission rate (OTR) decreased as a function of number of bilayers deposited, until a negligible value - below $0.005 \mathrm{~cm}^{3} /\left(\mathrm{m}^{2}\right.$ day atm) - was achieved with a 30-bilayer film, which was attributed to a brick wall nanostructure comprised of completely exfoliated clay. The resulting thin film, potentially microwaveable and with a good optical transparency (higher than 90\%), was presented as a good candidate for aluminum foil replacement in food packaging. The LbL assemblies swelled when exposed to high environmental humidity, which can be explained by decreasing the volume concentration of clay platelets and increasing distance between them (Wong, Rehfeldt, Hanni, Tanaka, \& Klitzing, 2004). Despite this effect, which increased permeability, the OTR at 95\% RH remained more than an order of magnitude lower than bare PET, thanks to electrostatic bonds that held the layers together, avoiding complete loss of barrier. In order to maintain a negligible OTR in the system, the authors (Jang et al., 2008) suggested combining it with a high moisture barrier.

\subsection{Cellulose-based nanoreinforcements}

\subsubsection{Structure and obtainment}

Cellulose, the building material of long fibrous cells, is a highly strong natural polymer. Cellulose nanofibers are inherently a low cost and widely available material. Moreover, they are environmentally friendly and easy of recycling by combustion, and require low energy consumption in manufacturing. All of this makes cellulose nanofibers an attractive class of nanomaterials for elaboration of low cost, lightweight, and high-strength nanocomposites (Helbert, Cavaillé, \& Dufresne, 1996; Podsiadlo et al., 2005).

Basically two types of nanoreinforcements can be obtained from cellulose - microfibrils and whiskers (Azizi Samir et al., 2005). In plants or animals the cellulose chains are synthesized to form microfibrils (or nanofibers), which are bundles of molecules that are elongated and stabilized through hydrogen bonding 


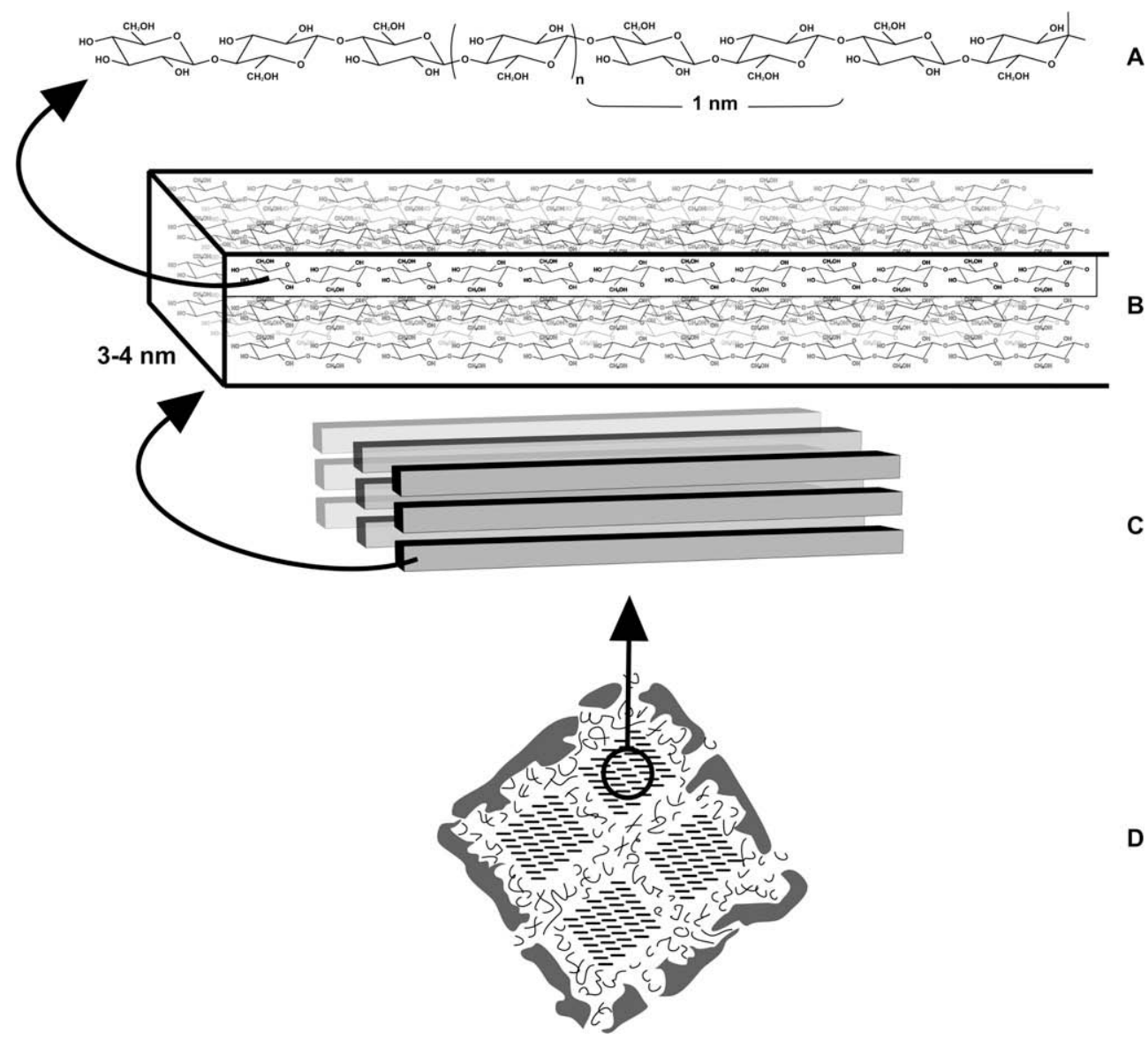

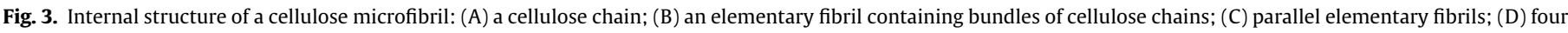
microfibrils held together by hemicellulose and lignin. (Adapted from Ramos, 2003).

(Azizi Samir et al., 2005; Wang \& Sain, 2007). Fig. 3 presents a schematic model of the structure of a microfibril. The microfibrils have nanosized diameters (2-20 nm, depending on the origin), and lengths in the micrometer range (Azizi Samir et al., 2005; Oksman, Mathew, Bondeson, \& Kvien, 2006). Each microfibril is formed by aggregation of elementary fibrils, which are made up of crystalline and amorphous parts. The crystalline parts, which can be isolated by several treatments, are the whiskers, also known as nanocrystals, nanorods, or rodlike cellulose microcrystals (Azizi Samir, Alloin, Sanchez, \& Dufresne, 2004; Dujardin, Blaseby, \& Mann, 2003), with lengths ranging from $500 \mathrm{~nm}$ up to $1-2 \mu \mathrm{m}$, and about 8-20 nm or less in diameter (Azizi Samir et al., 2004; Lima \& Borsali, 2004), resulting in high aspect ratios. Each microfibril can be considered a string of whiskers, linked along it by amorphous domains (which act as structural defects), and having a modulus close to that of a crystal of native cellulose (about $150 \mathrm{GPa}$ ) and a strength of about $10 \mathrm{GPa}$ (Helbert et al., 1996) - values which are only about seven times lower than those of single-walled carbon nanotubes (Podsiadlo et al., 2005).

The main method used to obtain cellulose whiskers has been acid hydrolysis, consisting basically in removing the amorphous regions present in the fibrils leaving the crystalline regions intact; the dimensions of the whiskers after hydrolysis depend on the percentage of amorphous regions in the bulk fibrils, which varies for each organism (Gardner, Oporto, Mills, \& Azizi Samir, 2008). Cellulose whiskers are not yet commercially available, instead microcrystalline cellulose (MCC), a closely related item, is available. MCC is formed by particles of hydrolyzed cellulose consisting of a very large amount of cellulose microcrystals together with amor- phous areas (Petersson \& Oksman, 2006a). MCC is prepared by removing part of the amorphous regions by acid degradation leaving the less accessible crystalline regions as fine crystals of typically $200-400 \mathrm{~nm}$ in length and an aspect ratio of about 10 . Degree of polymerization (DP) is about $140-400$, depending on the cellulose source and treatment procedure $(\mathrm{Wu}$, Henriksson, Liu, \& Berglund, 2007).

Bacterial cellulose sometimes have widths already in the nanometer range, even before processing (Nakagaito, Iwamoto, \& Yano, 2005; Sun, Zhou, Wu, \& Yang, 2007), and this has made bacterial cellulose a starting material of choice for several researchers (Brown \& Laborie, 2007; Dammström, Salmén, \& Gatenholm, 2005; Dammström et al., 2005; Kim, Jung, Kim, \& Jin, 2009; Yano, Maeda, Nakajima, Hagiwara, \& Sawaguchi, 2008).

\subsubsection{Factors affecting performance of cellulose nanoreinforcements}

The resulting properties of nanocomposites with cellulose fibers have been reported to be strongly related to the dimensions and consequent aspect ratio of the fibers, as well to geometric and mechanical percolation effects (Dubief et al., 1999; Hubbe, Rojas, Lucia, \& Sain, 2008). Aspect ratios are related to the origin of the cellulose used and whisker preparation conditions (Azizi Samir et al., 2005).

Dogan and McHugh (2007) observed that a microcrystalline cellulose (MCC) with submicron sized diameters had a much higher effect on tensile strength of hydroxyl propyl methyl cellulose (HPMC) than that of a micron sized MCC counterpart; moreover, the negative impact of micron sized MCC on elongation of the films was much more dramatic than that of its submicron sized counter- 
part. Chen, Liu, Chang, Cao, and Anderson (2009) produced composites of a pea starch matrix added with cellulose whiskers extracted from pea hull fibers with different hydrolysis times, which resulted in different aspect ratios. The composite produced by using the whiskers with the highest aspect ratio exhibited the highest transparency and best tensile properties.

On the other hand, Jiang, Liu, Zhang, Wang, and Wang (2007) demonstrated that the mean aspect ratio cannot be considered without proper assumptions; one must also consider the orientation distribution of the fillers. When the fillers does not follow a symmetric distribution, the overall mechanical properties obtained by the average aspect ratio of the fillers may be greatly different from those obtained when considering the aspect ratio distribution.

The orientation of cellulose fibers can greatly improve the tensile properties of a resulting nanocomposite. Kvien and Oksman (2007) applied a magnetic field to a nanocomposite of polyvinyl alcohol (PVOH) with cellulose whiskers to orient the whiskers; the modulus of the resulting nanocomposite was greatly increased by orientation.

Percolation theory predicts a maximum improvement in composite properties when there are just enough fillers to form a continuous structure, since they are properly dispersed within the matrix (Helbert et al., 1996; Ljungberg et al., 2005), which means that modulus and strength are expected to be improved if each fiber is in contact with two more others, on average (Hubbe et al., 2008). Chakraborty, Sain, and Kortschot (2006) reported a 2.5-fold increase in modulus of PVOH when 5\% fibers were added, but further increases in fiber contents were not helpful. So, the higher the aspect ratio of the fibers, the better the film performance, even at low fiber contents.

\subsubsection{Applications and effects on polymers matrices}

Cellulose nanoreinforcements have been reported to have a great effect in improving modulus of polymer matrices (Bhatnagar \& Sain, 2005; Helbert et al., 1996; Wu et al., 2007). For example, Helbert et al. (1996) reported that a poly(styrene-co-butyl acrylate) latex film containing $30 \mathrm{wt}$.\% of straw cellulose whiskers presented a modulus more than a thousand times higher than that of the bulk matrix. According to those authors (Helbert et al., 1996), such a great effect is ascribed not only to the geometry and stiffness of the whiskers, but also to the formation of a fibril network within the polymer matrix, the cellulose fibers being probably linked through hydrogen bonds. Zimmermann, Pöhler, and Geiger (2004) observed that fibril contents of up to $5 \%$ resulted in no strength or stiffness improvement of PVOH composites, and they suggested that probably a minimum fibril content is required to induce intense interactions between fibrils and thus the formation of networks. Moreover, cellulose fibers have been effective to improve strength and modulus of polymers, especially at temperatures above the glass transition temperature $\left(T_{\mathrm{g}}\right)$ of the matrix polymer (Dufresne, Dupeyre, \& Vignon, 2000; Dufresne \& Vignon, 1998); on the other hand, they tend to hinder elongation (Dogan \& McHugh, 2007; Freire et al., 2008; Kim et al., 2009; Ljungberg et al., 2005; Lu, Weng, \& Cao, 2005; Tang \& Liu, 2008; Wang \& Sain, 2007). However, other studies reported that even polymer elongation was improved by the fibers (Petersson \& Oksman, 2006b; Zimmermann et al., 2004), or at least the elongation was not significantly affected by them (Iwatake, Nogi, \& Yano, 2008). $\mathrm{Wu}$ et al. (2007) observed that, while the elongation of polyurethane was improved by cellulose nanofibrils, it was decreased by a conventional microscale cellulose filler. Such differences are possibly related to different degrees of matrix-cellulose interactions. According to Jordan et al. (2005), the addition of nanoreinforcements with poor interaction with the matrix causes the elongation and the strength of the material to decrease; on the other hand, the modulus seems not to be dependent on such interactions.

Starch-based materials have been extensively investigated as a choice product to improve biodegradability of a variety of plastics. However, the brittleness of starch requires the use of plasticizers such as polyols, which improve starch flexibility but, on the other hand, decreases its thermomechanical properties. The addition of whiskers to starch systems enhances their thermomechanical properties, reduces the water sensitivity, and keeps their biodegradability properties (Lima \& Borsali, 2004). Several articles have focused effects of cellulose nanoreinforcements on performance of starch. Some authors (Alemdar \& Sain, 2008; Anglès \& Dufresne, 2000) reported a $T_{\mathrm{g}}$ increasing effect of cellulose nanofibers on starch. According to Anglès and Dufresne (2001), this reinforcing effect depends strongly on the formation of a cellulose microfibrils network within the matrix, resulting from hydrogen bonds which can be formed during the evaporation step. The water uptake by starch films decreases linearly (Dufresne \& Vignon, 1998; Dufresne et al., 2000) or almost linearly (Lu et al., 2005) with increasing cellulose whisker content. A reduction in starch brittleness by cellulose whiskers was also reported by Dufresne and Vignon (1998), which is consistent with the transcrystallization phenomenon, i.e., orientation of crystals of a semicrystalline matrix perpendicularly to the cellulose microfibrils, as described by Helbert and Chanzy (1994) and Hulleman, Helbert, and Chanzy (1996).

Moisture barrier of polymer films has been observed to be improved by cellulose nanoreinforcements (Paralikar, Simonsen, \& Lombardi, 2008; Sanchez-Garcia, Gimenez, \& Lagaron, 2008; Svagan, Hedenqvist, \& Berglund, 2009). The presence of crystalline fibers is thought to increase the tortuosity in the materials leading to slower diffusion processes and, hence, to lower permeability (Sanchez-Garcia et al., 2008). The barrier properties are enhanced if the filler is less permeable, and have good dispersion in the matrix and a high aspect ratio (Lagaron, Catalá, \& Gavara, 2004).

Nanosized cellulose fibrils have been also reported to improve thermal properties of polymers. The thermal stability of polymers in nanocomposites with cellulose whiskers was reported to be improved when compared to those of the corresponding bulk polymers (Helbert et al., 1996; Oksman et al., 2006; Petersson, Kvien \& Oksman, 2007). On the other hand, their effects on $T_{\mathrm{g}}$ of polymers have been controversial. Some authors reported $T_{\mathrm{g}}$ increasing effects on polymer films (Alemdar \& Sain, 2008; Anglès \& Dufresne, 2000). Differently, in other studies the effect of cellulose nanoreinforcements on $T_{\mathrm{g}}$ was not consistent (Azizi Samir et al., 2004; Mathew \& Dufresne, 2002; Sanchez-Garcia et al., 2008) or even negligible (Azizi Samir et al., 2004). Mathew and Dufresne (2002) observed that $T_{\mathrm{g}}$ of a sorbitol-plasticized starch nanocomposite with tunicin whiskers first increased up to a whisker content around $10-15 \mathrm{wt} . \%$ and then decreased. The increase of $T_{\mathrm{g}}$ up to 15 wt.\% whiskers addition was ascribed to the increase in the crystallinity of the starch matrix with tunicin content, the restricted mobility of amorphous amylopectin chains resulting from the physical cross-links induced by the crystallization. For the decrease of $T_{\mathrm{g}}$ above $15 \mathrm{wt}$.\% whiskers, a possible explanation could be that sorbitol is probably at least partially ejected from the crystalline domains during crystallization, and this ejection increases its concentration in the amorphous domains of the matrix. This phenomenon should compete with the increase of $T_{\mathrm{g}}$ upon whiskers addition and becomes most probably predominant at high loading level inducing a decrease of $T_{\mathrm{g}}$. For the studies reporting negligible variation of $T_{\mathrm{g}}$ values of polymers according to contents of cellulose nanoreinforcements in composites, two studies presented possible explanations. According to Wu et al. (2007), the presence of cellulose nanofibrils results in a smaller portion of the matrix participating in the glass transition rather than a consistent increase in $T_{\mathrm{g}}$. Azizi Samir et al. (2004) proposed another mechanism, accord- 
ing to which the presence of whiskers could influence $T_{\mathrm{g}}$ values in two opposite ways. First, the solid surface of cellulose whiskers could restrict mobility of polymer chains in the vicinity of the interfacial area, which would result in a global shift of $T_{\mathrm{g}}$ toward higher temperatures. In an opposite way, those authors (Azizi Samir et al., 2004) mentioned that the cross-linking density of the polymeric matrix was decreased in the presence of whiskers, which would indirectly decrease $T_{\mathrm{g}}$.

\subsubsection{Improving compatibility between cellulose nanofibers and hydrophobic matrices}

Chemical compatibility between the filler and the matrix plays a critical role in the filler dispersion within the matrix and in the adhesion between both phases Hubbe et al., 2008). Because of their hydrophilic surface, interactions between cellulose fibrils and hydrophilic matrices are usually satisfactory (Bondeson \& Oksman, 2007). "All-cellulose composites" (in which both the reinforcing fiber and the matrix are cellulose based) is an especially interesting group of composites, since it has the advantage of the excellent interaction between the fiber and the matrix which is critical for good mixing characteristics and for the mechanical performance of the composites (Nishino, Matsuda, \& Hirao, 2004). On the other hand, the use of cellulose whiskers in nanocomposites with hydrophobic matrices results frequently in weak filler-matrix interactions (Hubbe et al., 2008). When added to non-polar matrices, the highly polar surface of cellulose fibers results in some problems: low interfacial compatibility with the matrices, low moisture resistance/barrier, and inter-fiber aggregation by hydrogen bonding (Freire et al., 2008). Another limitation to the application of cellulose fibrils, also related to its hydrophilic surface, is their high water absorption capacity, which is undesirable in many potential applications (Hubbe et al., 2008).

Bondeson and Oksman (2007) investigated the possibility to use $\mathrm{PVOH}$ to improve dispersion of cellulose whiskers in a PLA matrix. However, PLA and PVOH formed two immiscible phases with a continuous PLA phase and a discontinuous PVOH phase, most whiskers having located in the $\mathrm{PVOH}$ phase. As a result, the thermal stability and the mechanical properties of the nanocomposites were not improved compared to its unreinforced counterpart.

A variety of surface modifications on cellulose nanoreinforcements can greatly improve their miscibility within hydrophobic matrices. Cellulosic surfaces can be derivatized by several reactions involving the hydroxyl groups, such as esterifications, so as to improve their compatibility with less polar polymers (Mohanty, Misra, \& Drzal, 2001). Freire et al. (2008) modified cellulose fibers by acylation with fatty acids in order to prepare them for composites with polyethylene (PE). The surface chemical modification of the cellulose fibers resulted in improved interfacial adhesion between the fibers and the matrix, which was evidenced by enhanced mechanical properties and thermal stability. Moreover, the water uptake capacity of the material was decreased.

Surfactant addition can also improve the compatibility between cellulose and hydrophobic matrices (Lima \& Borsali, 2004; Ljungberg et al., 2005; Petersson, Kvien, \& Oksman, 2007). Hubbe et al. (2008) proposed that the hydrophilic head group of the surfactant adsorbs on the cellulose surface whereas its hydrophobic tail solves in the matrix, avoiding aggregation of cellulose fillers via steric stabilization; the improved performance of the nanocomposite would be explained not only by a better wettability and adhesion between phases, but also by a more uniform distribution of the fillers within the matrix.

Grafting between a hydrophobic matrix and hydrophilic fibers can also improve their otherwise poor adhesion. Mokoena, Djoković, and Luyt (2004) reported that composites with $1 \%$ dicumyl peroxide (DCP), a cross-linking agent which was used to induce grafting between a PE matrix and cellulose fibers from sisal, pre- sented much improved strength than composite with untreated fibers.

\subsection{Carbon nanotubes}

Carbon nanotubes (CNTs) may consist of a one-atom thick single-wall nanotube (SWNT), or a number of concentric tubes called multiwalled nanotubes (MWNT), having extraordinarily high aspect ratios and elastic modulus (Zhou, Shin, Wang, \& Bakis, 2004). Lau and Hui (2002) reported CNTs to have theoretical elastic modulus and tensile strength values as high as $1 \mathrm{TPa}$ and $200 \mathrm{GPa}$, respectively.

Kim, Han, and Hong (2008) modified CNTs by introducing carboxylic acid groups on their surfaces in order to enhance their intermolecular interactions with the poly(ethylene-2,6-naphtalene) (PEN) matrix. CNTs, even in concentrations as low as $0.1 \mathrm{wt} . \%$, greatly improved thermal stability as well as tensile strength and modulus of PEN. Other polymers have been found to have their tensile strength/modulus improved by addition of CNTs, such as PVOH (Bin, Mine, Koganemaru, Jiang, \& Matsuo, 2006; Chen, Tao, Xue, \& Cheng, 2005), polypropylene (López Manchado, Valentini, Biagotti, \& Kenny, 2005; Prashantha et al., in press) and polyamide (Zeng et al., 2006). According to Brody (2006), researches from Natick indicated that a CNT nanocomposite with PLA exhibited a $200 \%$ better water vapor transmission rate than pure PLA, plus increased modulus and toughness.

\subsection{Silica $\left(\mathrm{SiO}_{2}\right)$}

Silica nanoparticles $\left(\mathrm{nSiO}_{2}\right)$ have been reported to improve mechanical and/or barrier properties of several polymer matrices. Wu, Zhang, Rong, and Friedrick (2002) observed that the addition of $\mathrm{nSiO}_{2}$ into a polypropylene (PP) matrix improved tensile properties of the material - not only strength and modulus, but also elongation. Improvements in tensile properties - again including elongation - were also reported for a starch matrix as resulting from $\mathrm{nSiO}_{2}$ addition (Xiong, Tang, Tang, \& Zou, 2008). Those authors (Xiong et al., 2008) observed also that $\mathrm{nSiO}_{2}$ addition decreased water absorption by starch. Vladimiriov, Betchev, Vassiliou, Papageorgiou, and Bikiaris (2006) incorporated $\mathrm{nSiO}_{2}$ to an isotactic polypropylene (iPP) matrix, using maleic anhydride grafted polypropylene (PP-g-MA) as a compatibilizer. $\mathrm{nSiO}_{2}$ increased storage modulus of iPP, making the material stiffer, and improved the oxygen barrier of the matrix. Jia, Li, Cheng, Zhang, and Zhang (2007) prepared nanocomposites of $\mathrm{PVOH}$ with $\mathrm{nSiO}_{2}$ by radical copolymerization of vinyl silica nanoparticles and vinyl acetate. The nanocomposites had improved thermal and mechanical properties when compared to the pure $\mathrm{PVOH}$, due to strong interactions between $\mathrm{nSiO}_{2}$ and the polymer matrix via covalent bonding. Tang, Zou, Xiong, and Tang (2008) prepared starch/ $\mathrm{PVOH} / \mathrm{nSiO}_{2}$ biodegradable films. With the increase in $\mathrm{nSiO}_{2}$ content, the tensile properties and water resistance of the films were improved. There was also an increase in the intermolecular hydrogen bonds, as well as formation of $\mathrm{C}-\mathrm{O}-\mathrm{Si}$ groups, between $\mathrm{nSiO}_{2}$ and starch, or $\mathrm{nSiO}_{2}$ and $\mathrm{PVOH}$, which improved the miscibility and compatibility between film components. Some authors ( Wu et al., 2002; Zhang \& Rong, 2003) observed that the presence of grafting polymers on the surface of $\mathrm{nSiO}_{2}$ improved the tailorability of the composites, that is to say, different species of grafting monomers result in different interfacial interactions and tensile properties.

\subsection{Starch nanocrystals}

Native starch granules can be submitted to an extended-time hydrolysis at temperatures below the gelatinization temperature, 
when the amorphous regions are hydrolyzed allowing separation of crystalline lamellae, which are more resistant to hydrolysis. The starch crystalline particles show platelet morphology with thicknesses of 6-8 nm (Kristo \& Biliaderis, 2007).

Kristo and Biliaderis (2007) reported that the addition of starch nanocrystals (SNC) improved tensile strength and modulus of pullulan films, but decreased their elongation. The $T_{\mathrm{g}}$ values shifted to higher temperatures with increasing SNC content, which was attributed to a restricted mobility of pullulan chains due to the formation of strong interactions between SNC as well as between filler and matrix. The water vapor permeability of pullulan films was decreased by addition of $20 \%$ or more SNC. Addition of SNC to PVOH resulted in different effects, according to Chen, Cao, Chang, and Huneault (2008), who observed that the tensile strength and elongation of $\mathrm{PVOH}$ were only slightly improved by addition of SNC up to $10 \mathrm{wt} . \%$; above this content, such properties became lower than that of pure PVOH. The properties of the PVOH composite with SNC, on the other hand, were better than those obtained when native starch was used instead of SNC, suggesting that SNC dispersed more homogeneously and formed stronger interactions with PVOH than native starch granules.

\subsection{Chitin/chitosan nanoparticles}

Lu, Weng, and Zhang (2004) and Sriupayo, Supaphol, Blackwell, and Rujiravanit (2005) prepared chitin whiskers by acid hydrolysis of chitin. The average dimensions of the whiskers obtained by Lu et al. (2004) were $500 \mathrm{~nm}$ (length) and $50 \mathrm{~nm}$ (diameter), and those obtained by Sriupayo et al. (2005) had $417 \mathrm{~nm}$ (length) and $33 \mathrm{~nm}$ (diameter). Lu et al. (2004) added chitin whiskers to soy protein isolate (SPI) thermoplastics, and reported that the whiskers greatly improved not only the tensile properties (tensile strength and elastic modulus) of the matrix, but also its water resistance. Sriupayo et al. (2005) added chitin whiskers to chitosan films, and observed that the whiskers improving chitosan tensile strength until a whisker content of $2.96 \%$, while higher increases of whiskers contents resulted in decreasing strength. The elongation of the films was impaired by addition of whiskers up to $2.96 \%$, and then it leveled off at higher whiskers contents. The addition of $\alpha$-chitin whiskers improved water resistance of the films.

Chitosan nanoparticles can be obtained by ionic gelation, where the positively charged amino groups of chitosan form electrostatic interactions with polyanions employed as cross-linkers, such as tripolyphosphate (López-León, Carvalho, Seijo, Ortega-Vinuesa, \& Bastos-González, 2005). De Moura et al. (2009) prepared chitosan-tripolyphosphate (CS-TPP) nanoparticles and incorporated them into hydroxypropyl methylcellulose (HPMC) films. Addition of CS-TPP nanoparticles significantly improved mechanical and barrier properties of the films. The authors attributed such effects to the nanoparticles filling discontinuities in the HPMC matrix.

\section{Antimicrobial nanocomposites}

The incorporation of antimicrobial compounds into food packaging materials has received considerable attention. Films with antimicrobial activity could help control the growth of pathogenic and spoilage microorganisms. An antimicrobial nanocomposite film is particularly desirable due to its acceptable structural integrity and barrier properties imparted by the nanocomposite matrix, and the antimicrobial properties contributed by the natural antimicrobial agents impregnated within (Rhim \& Ng, 2007). Materials in the nanoscale range have a higher surface-to-volume ratio when compared with their microscale counterparts. This allows nanomaterials to be able to attach more copies of biological molecules, which confers greater efficiency (Luo \& Stutzenberger, 2008).
Nanoscale materials have been investigated for antimicrobial activity so that they can be used as growth inhibitors (Cioffi et al., 2005), killing agents (Huang et al., 2005; Kumar \& Münstedt, 2005; Lin, Li, Wang, Huang, \& Duan, 2005; Qi, Xu, Jiang, Hu, \& Zou, 2004; Stoimenov, Klinger, Marchin, \& Klabunde, 2002), or antibiotic carriers (Gu, Ho, Tong, Wang, \& Xu, 2003).

The most common nanocomposites used as antimicrobial films for food packaging are based on silver, which is well known for its strong toxicity to a wide range of microorganisms (Liau, Read, Pugh, Furr, \& Russell, 1997), with high temperature stability and low volatility (Kumar \& Münstedt, 2005). Some mechanisms have been proposed for the antimicrobial property of silver nanoparticles (Ag-NPs): adhesion to the cell surface, degrading lipopolysaccharides and forming "pits" in the membranes, largely increasing permeability (Sondi \& Salopek-Sondi, 2004); penetration inside bacterial cell, damaging DNA (Li et al., 2008); and releasing antimicrobial $\mathrm{Ag}^{+}$ions by Ag-NPs dissolution (Morones et al., 2005). The latter mechanism is consistent with findings by Kumar and Münstedt (2005), who affirmed that the antimicrobial activity of silver-based polymers depends on releasing of $\mathrm{Ag}^{+}$, which binds to electron donor groups in biological molecules containing sulphur, oxygen or nitrogen.

Chemical reduction is the most common method for preparation of Ag-NPs as stable, colloidal dispersions. The reduction of $\mathrm{Ag}^{+}$in aqueous solution produces colloidal silver with particle diameters of several nanometers (Wiley, Sun, Mayers, \& Xia, 2005). Initially, the reduction leads to the formation of silver atoms $\left(\mathrm{Ag}^{0}\right)$ and their subsequent aggregation into oligomeric clusters, which leads to the formation of Ag particles (Kapoor, Lawless, Kennepohl, Meisel, \& Serpone, 1994). The synthesis is often performed in the presence of stabilizers in order to avoid undesirable agglomeration of colloids (Sharma, Yngard, \& Lin, 2009). Kvítek et al. (2008) studied the influence of surfactants and polymers on aggregation stability and antibacterial activity of Ag-NPs, and reported that modified Ag-NPs had improved bactericidal effect. A correlation was found between the aggregation stability and antibacterial activity. Ag-NPs has been successfully tested as an antimicrobial material (Aymonier et al., 2002; Son, Youk, \& Park, 2006; Sondi \& Salopek-Sondi, 2004; Tankhiwale \& Bajpai, 2009; Yu et al., 2007). Smaller Ag-NPs, having larger surface area available for interaction with microbial cells, result in better bactericidal effect than larger Ag particles (An, Zhang, Wang, \& Tang, 2008; Kvítek et al., 2008).

Silver nanocomposites have been produced by several researchers, and their antimicrobial effectivity has usually been reported. Damm, Münstedt, and Rösch (2008), comparing efficacy of polyamide 6/silver-nano- and microcomposites, reported that nanocomposites with a low silver content presented a better increased efficacy against Escherichia coli than microcomposites with a much higher silver content. Damm, Münstedt, and Rösch (2007) reported that polyamide 6 filled with 2 wt.\% Ag-NPs was effective against $E$. coli, even after immersed in water for 100 days. Moreover, Ag-NPs absorbs and decomposes ethylene ( $\mathrm{Hu} \& \mathrm{Fu}$, 2003), which may contribute to its effects on extending shelf life of fruits and vegetables. Indeed, Li et al. (2009) reported that a nanocomposite PE film with Ag-NPs retarded the senescence of jujube, a Chinese fruit. An et al. (2008) reported that a coating containing Ag-NPs was effective in decreasing microbial growth and increasing shelf life of asparagus. Ag-NPs were also reported by Mbhele et al. (2003) to increase modulus and strength of a PVOH matrix, and to improve its thermal properties, enhancing its stability and increasing its $T_{\mathrm{g}}$.

Nanostructured calcium silicate (NCS) was used by Johnston et al. (2008) to adsorb $\mathrm{Ag}^{+}$from solution down to the $1 \mathrm{mg} \mathrm{kg}^{-1}$ level. The resulting NCS-Ag composite exhibited effective antimicrobial activity at desirably low levels of silver down to $10 \mathrm{mg} \mathrm{kg}^{-1}$, 
and could be incorporated into food packaging as an antimicrobial agent.

Titanium dioxide $\left(\mathrm{TiO}_{2}\right)$ is widely used as a photocatalytic disinfecting material for surface coatings (Fujishima, Rao, \& Tryk, 2000). $\mathrm{TiO}_{2}$ photocatalysis, which promotes peroxidation of the polyunsaturated phospholipids of microbial cell membranes (Maness et al., 1999), has been used to inactivate several food-related pathogenic bacteria (Kim, Kim, Cho, \& Cho, 2003; Kim, Lee, Park, Kim, \& Cho, 2005; Robertson, Robertson, \& Lawton, 2005). Chawengkijwanich and Hayata (2008) developed a $\mathrm{TiO}_{2}$ powder-coated packaging film and verified its ability to reduce $E$. coli contamination on food surfaces, suggesting that the film could be used for freshcut produce. Gelover, Gómez, Reyes, and Leal (2006) demonstrated the efficacy of $\mathrm{TiO}_{2}$-coated films exposed to sunlight to inactivate fecal coliforms in water. Metal doping improves visible light absorbance of $\mathrm{TiO}_{2}$ (Anpo et al., 2001) and increases its photocatalytic activity under UV irradiation (Choi, Termin, \& Hoffmann, 1994). It has been demonstrated that doping $\mathrm{TiO}_{2}$ with silver greatly improved photocatalytic bacterial inactivation (Page et al., 2007; Reddy, Venugopal, \& Subrahmanyam, 2007). This combination was used by Cheng, Li, Pavlinek, Saha, and Wang (2006), who obtained good antibacterial properties from $\mathrm{TiO}_{2} / \mathrm{Ag}^{+}$nanoparticles in a nanocomposite with PVC.

Qi et al. (2004) have reported antibacterial activity of nanoscale chitosan. One possible antimicrobial mechanism proposed by those authors involves interactions between positively charged chitosan and negatively charged cell membranes, increasing membrane permeability and eventually causing rupture and leakage of intracellular material. This is consistent with the observation that both raw chitosan and engineered nanoparticles are ineffective at $\mathrm{pH}$ values above 6 , which would be due to the absence of protonated amino groups (Qi et al., 2004). Another two antimicrobial mechanisms were proposed by Rabea, Badawy, Stevens, Smagghe, and Steurbaut (2003): chelation of trace metals by chitosan, inhibiting enzyme activities; and, in fungal cells, penetration through the cell wall and membranes to bind DNA and inhibit RNA synthesis.

CNTs have been also reported to have antibacterial properties. Direct contact with aggregates of CNTs was demonstrated to be fatal for E. coli, possibly because the long and thin CNTs puncture microbial cells, causing irreversible damages (Kang, Pinault, Pfefferle, \& Elimelech, 2007). On the other hand, there are studies suggesting that CNTs are cytotoxic to human cells, at least when in contact to skin (Monteiro-Riviere, Nemanich, Inman, Wang, \& Riviere, 2005; Shvedova et al., 2003) and lungs (Warheit et al., 2004), which would affect people working directly with CNTs in processing stages rather than consumers. Nevertheless, it is mandatory to know eventual health effects of CNTs when ingested, since the risk of ingestion of particles incorporated to a food packaging material must be taken into account because of the possibility of migration to food.

Haynie, Zhang, Zhao, and Rudra (2006) suggested that antimicrobial peptides, such as nisin, could be integrated with LbL structures to develop antimicrobial films. Nisin acts as a depolarization agent on bacterial membranes (Ruhr \& Sahl, 1985), and creates pores in lipid bilayers (Sahl, Kordel, \& Benz, 1987). Multilayer peptide nanofilms were produced by Li, Rozas, and Haynie (2006), who intercalated different peptides designed to be oppositely charged at neutral $\mathrm{pH}$. Disulfide (S-S) cross-linking resulted in formation of a three-dimensional network which was much more stable than when the peptide film was stabilized only by electrostatic interactions.

\section{Oxygen scavenging films}

Oxygen $\left(\mathrm{O}_{2}\right)$ is responsible for the deterioration of many foods either directly or indirectly. Direct oxidation reactions result in browning of fruits and rancidity of vegetable oils, to name a few examples. Food deterioration by indirect action of $\mathrm{O}_{2}$ includes food spoilage by aerobic microorganisms. The incorporation of $\mathrm{O}_{2}$ scavengers into food package can maintain very low $\mathrm{O}_{2}$ levels, which is useful for several applications. Attention has particularly focused on the photocatalytic activity of nanocrystalline titania $\left(\mathrm{TiO}_{2}\right)$ under ultraviolet radiation (Xiao-e, Green, Haque, Mills, \& Durrant, 2004).

Oxygen scavenger films were successfully developed by Xiao-e et al. (2004), by adding titania nanoparticles to different polymers. The authors suggested their use for packaging a wide variety of oxygen-sensitive products. Since $\mathrm{TiO}_{2}$ act by a photocatalytic mechanism, its major drawback is the requirement of UVA light (Mills, Doyle, Peiro, \& Durrant, 2006).

\subsection{Nano-based sensors}

Nanoparticles can be applied as reactive particles in packaging materials. The so-called nanosensors are able to respond to environmental changes (e.g., temperature or humidity in storage rooms, levels of oxygen exposure), degradation products or microbial contamination (Bouwmeester et al., 2009).

The food expiration date is estimated by industries by considering distribution and storage conditions (especially temperature) to which the food product is predicted to be exposed. However, it is not unknown that such conditions are not always the real ones, and foods are frequently exposed to temperature abuse; this is especially worrying for products which require a cold chain. Moreover, micropores or sealing defects in packaging systems can lead food products to an unexpected high exposure to oxygen, which can result in undesirable changes. When integrated into food packaging, nanosensors can detect certain chemical compounds, pathogens, and toxins in food, being then useful to eliminate the need for inaccurate expiration dates, providing real-time status of food freshness (Liao, Chen, \& Subramanian, 2005).

According to Hongda Chen (USDA, Washington, DC), nanobased sensors to detect pathogens, spoilage, chemical contaminants, or product tampering, or to track ingredients or products through the processing chain are already under development or have been commercialized (Nachay, 2007). Mahadevan Iyer (Georgia Tech Packaging Research Center, Atlanta, GA) pointed out several advantages of these sensors, based on CNT, over the expensive and time consuming conventional detection methods such as HPLC. He mentioned the rapid and high-throughput detection; the simplicity and cost effectiveness; the reduced power requirements and easier recycling; and the unnecessity of exogenous molecules or labels. Iyers have been working on development of a multiwalled CNT-based biosensor which can detect microorganisms, toxic proteins, and degraded products in food and beverages (Nachay, 2007).

\subsection{Detection of gases produced by food spoilage}

Based on applied studies of the surface properties of materials, several types of gas sensors have been developed, which translates chemical interactions between particles on the surfaces into a response signal. Metal oxide gas sensors are one of the most popular type of sensors because of their high sensitivity and stability (Šetkus, 2002).

Conducting polymers (CPs) or electro active conjugated polymers, which can be synthesized either by chemical or electrochemical oxidation, are very important because of their electrical, electronic, magnetic and optical properties, which are related to their conjugated $\pi$ electron backbones (Ahuja, Mir, Kumar, \& Rajesh, 2007; Retama, 2005). Polyene and polyaromatic CPs such as polyaniline (PANI), polyacetylene, polypyrrole (PPy) have been widely studied (Ahuja et al., 2007). Electrochemically polymerized 
CPs have a remarkable ability to switch between conducting oxidized (doped) and insulating reduced (undoped) state, which is the basis of many applications (Rajesh, Takashima, \& Kaneto, 2004).

Food spoilage is caused by microorganisms, whose metabolism produces gases which can be detected by conducting polymer nanocomposites (CPC) or metal oxides, which can be used for quantification and/or identification of microorganisms based on their gas emissions. Sensors based on CPC consist on conducting particles embedded into an insulating polymer matrix. The resistance changes of the sensors produce a pattern that corresponds to the gas under investigation (Arshak et al., 2007).

Arshak et al. (2007) developed CPC sensors containing carbon black and polyaniline to detect and identify food borne pathogens by producing a specific response pattern for each microorganism. Three bacteria (Bacillus cereus, Vibrio parahemolyticus and Salmmonella spp.) could be identified from the response pattern produced by the sensors. Chicken meat freshness was evaluated by Galdikas, Mironas, Senulienè, Šetkus, and Zelenin (2000), basing on the smell when the output data of metal (tin and indium) oxide gas sensors were processed with a neural network.

Kraft Foods, along with researchers at Rutgers University (NJ), have been developing an "electronic tongue" to be incorporated in food packaging. The device consists of an array of nanosensors extremely sensitive to gases released by spoiling microorganisms, producing a color change which indicates whether the food is deteriorated (Joseph \& Morrison, 2006).

\section{3. $\mathrm{O}_{2}$ indicators}

Oxygen allows aerobic microorganism to grow during food storage. There has been an increasing interest to develop non-toxic and irreversible oxygen sensors to assure oxygen absence in oxygenfree food packaging systems, such as packaging under vacuum or nitrogen.

Lee, Sheridan, and Mills (2005) developed an UV-activated colorimetric oxygen indicator, which uses nanoparticles of titania $\left(\mathrm{TiO}_{2}\right)$ to photosensitize the reduction of methylene blue (MB) by triethanolamine in a polymer encapsulation medium, using UVA light. Upon UV irradiation, the sensor bleaches and remains colorless, until it is exposed by oxygen, when its original blue color is restored. The rate of color recovery is proportional to the level of oxygen exposure. Gutiérrez-Tauste, Domènech, Casañ-Pastor, and Ayllón (2007) deposited $\mathrm{MB} / \mathrm{TiO}_{2}$ nanocomposite thin films on glass by liquid phase deposition (LPD), a soft chemical technique which has been applied to deposition of oxides to several substrates. This technique could be used to develop oxygen indicator packaging systems for a variety of oxygen-sensitive foods.

Mills and Hazafy (2009) used nanocrystalline $\mathrm{SnO}_{2}$ as a photosensitizer in a colorimetric $\mathrm{O}_{2}$ indicator comprising a sacrificial electron donor (glycerol), a redox dye (methylene blue - MB), and an encapsulating polymer (hydroxyethyl cellulose). Exposure to UVB light led to activation (photobleaching) of the indicator and photoreduction of $\mathrm{MB}$ by the $\mathrm{SnO}_{2}$ nanoparticles. The color of the films varied according to $\mathrm{O}_{2}$ exposure - bleached when not exposed, and blue upon exposed.

\section{Nanoscale enzyme immobilization systems}

Enzymes are widely used by food industry for several applications. In some cases, the direct use of enzymes can be restricted by their sensitivity to processing conditions and/or to compounds which can inhibit their action, resulting in short operational life or inactivation. When immobilized in different tailored carriers, the enzymes can have improved stability to $\mathrm{pH}$ and temperature, resis- tance to proteases and other denaturing compounds, as well as an adequate environment for their repeated use or controlled release (Kandimalla, Tripathi, \& Ju, 2006; Lopez-Rubio, Gavara, \& Lagaron, 2006).

In the last decades, enzyme immobilization has been also considered for packaging applications (Appendini \& Hotchkiss, 1997; Soares \& Hotchkiss, 1998). The incorporation in the package of enzymes like lactase or cholesterol reductase could increase the value of the food product and answer the needs of consumers with enzyme-related health problems (Fernández, Cava, Ocio, \& Lagaron, 2008).

Nanoscale immobilization systems would have strongly enhanced performance, since they would increase the available surface contact area and modify the mass transfer, probably the most important factors affecting the effectiveness of such systems (Fernández et al., 2008). Numerous materials have been developed as support for biomolecules. Inorganic supports such as clays have a high affinity for protein adsorption, and been reported to be efficient enzyme carriers (Gopinath \& Sugunan, 2007; Sinegani, Emzitai, \& Shariamadari, 2005), so new approaches might be expected in the next years dealing with enzyme adsorption into clays incorporated to polymers, in order to control release of enzyme molecules (Rhim \& Ng, 2007). CPs can be used as immobilizing matrices for biomolecules (Ahuja et al., 2007), as reported by Sharma et al. (2004), who immobilized glucose oxidase onto films of poly(aniline-co-fluoroaniline). Silica nanoparticles have been modified to immobilize glutamate dehydrogenase and lactate dehydrogenase (Qhobosheane, Santra, Zhang, \& Tan, 2001). The immobilized enzymes have shown excellent activity, allowing the modified silica nanoparticles to be used for biosensing applications.

Several techniques can be used to produce films for enzyme immobilization. LbL assembly was used by Rudra et al. (2006) to obtain a polypeptide multilayer antimicrobial nanofilm constituted by negatively charged layers of poly(L-glutamic acid) and positively charged layers of egg white lysozyme, a chicken enzyme widely employed as a food preservative. The nanofilms were effective to inhibit growth of Micrococcus luteus. The authors demonstrated a simple control of the releasing rate of lisozyme by adjusting the amount of film layers. Caseli, Santos, Foschini, Gonçalves, and Oliveira (2007) successfully immobilized glucose oxidase (GO) in LbL films with chitosan. The enzyme activity was almost the same as in a homogeneous solution, confirming the suitability of the LbL technique for immobilization of GO, which could be used in several systems involving catalysis by this enzyme, such as biosensors.

Electrospinning is a simple and quick technique for producing nanofibers from a wide range of materials. It uses a strong electric field to eject a jet of a viscous polymer solution from a capillary. The jet solidifies via solvent evaporation or cooling, resulting in a fiber-based structure which allows the entrapment of bioactive molecules (Fernández et al., 2008; Huang, Zhang, Kotaki, \& Ramakrishna, 2003). The large specific surface area and the fine porous structure of electrospun nanofibers make them an excellent enzyme support, greatly increasing the catalyzing ability of immobilized enzymes (Wu, Yuan, \& Sheng, 2005), as demonstrated with $\alpha$ chymotrypsin (Jia et al., 2002), glucose oxidase (Ren et al., 2006), and cellulase (Wu et al., 2005).

\section{Final considerations}

The use of biopolymers by the food industry has faced feasibility problems related mainly to their relatively high cost and poor overall performance when compared to those of synthetic polymers. However, since industries are concerned with sustainable development, the production cost of biopolymers has decreased, 
allowing biopolymer-based materials to be increasingly developed. More important, nanocomposites promise to expand the use of edible and biodegradable films, since the addition of nanoreinforcements has been related to improvements in overall performance of biopolymers, enhancing their mechanical, thermal and barrier properties, usually even at very low contents. Thus, nanoparticles have an important role to improve feasibility of use of biopolymers for several application, including food packaging.

Moreover, several nanoparticles can provide active and/or "smart" properties to food packaging materials, such as antimicrobial properties, oxygen scavenging ability, enzyme immobilization, or indication of the degree of exposure to some degradation related factor. So, nanocomposites can not only passively protect the food against environmental factors, but also incorporate properties to the packaging material so it may actually enhance stability of foods, or at least to indicate their eventual inadequation to be consumed.

However, there are many safety concerns about nanomaterials, as their size may allow them to penetrate into cells and eventually remain in the system. There is no consensus about categorizing nanomaterials as new (or unnatural) materials. On one hand, the properties and safety of the materials in its bulk form are usually well known, but the nano-sized counterparts frequently exhibit different properties from those found at the macro-scale. There is limited scientific data about migration of most types of nanoparticles (NPs) from the packaging material into food, as well as their eventual toxicological effects. It is reasonable to assume that migration may occur, hence the need for accurate information on the effects of NPs to human health following chronic exposure is imperative.

\section{References}

Adame, D., \& Beall, G. W. (2009). Direct measurement of the constrained polymer region in polyamide/clay nanocomposites and the implications for gas diffusion. Applied Clay Science, 42, 545-552.

Ahuja, T., Mir, I. A., Kumar, D., \& Rajesh (2007). Biomolecular immobilization on conducting polymers for biosensing applications. Biomaterials, 28, 791-805.

Alemdar, A., \& Sain, M. (2008). Biocomposites from wheat straw nanofibers: morphology, thermal and mechanical properties. Composites Science and Technology, 68, 557-565.

Alexandre, M., \& Dubois, P. (2000). Polymer-layered silicate nanocomposites: preparation, properties and uses of a new class of materials. Materials Science and Engineering, 28, 1-63.

Alexandre, B., Langevin, D., Médéric, P., Aubry, T., Couderc, H., Nguyen, Q. T., et al. (2009). Water barrier properties of polyamide 12/montmorillonite nanocomposite membranes: structure and volume fraction effects. Journal of Membrane Science, 328(1-2), 186-204.

An, J., Zhang, M., Wang, S., \& Tang, J. (2008). Physical, chemical and microbiological changes in stored green asparagus spears as affected by coating of silver nanoparticles-PVP. LWT - Food Science and Technology, 41(6), 1100-1107.

Anglès, M. N., \& Dufresne, A. (2000). Plasticized starch/tunicin whiskers nanocomposites. 1. Structural analysis. Macromolecules, 33, 8344-8353.

Anglès, M. N., \& Dufresne, A. (2001). Plasticized starch/tunicin whiskers nanocomposite materials. 2. Mechanical behavior. Macromolecules, 34, 2921-2931.

Anpo, M., Kishiguchi, S., Ichihashi, Y., Takeuchi, M., Yamashita, H., Ikeue, K., et al. (2001). The design and development of second-generation titanium oxide photocatalysts able to operate under visible light irradiation by applying a metal ion-implantation method. Research on Chemical Intermediates, 27(4-5), 459-467.

Appendini, P., \& Hotchkiss, J. H. (1997). Immobilisation of lysozyme on food contact polymers as potential antimicrobial films. Packaging Technology and Science, 10, 271-279.

Arshak, K., Adley, C., Moore, E., Cunniffe, C., Campion, M., \& Harris, J. (2007). Characterisation of polymer nanocomposite sensors for quantification of bacterial cultures. Sensors and Actuators B, 126, 226-231.

Avella, M., De Vlieger, J. J., Errico, M. E., Fischer, S., Vacca, P., \& Volpe, M. G. (2005). Biodegradable starch/clay nanocomposite films for food packaging applications. Food Chemistry, 93, 467-474.

Aymonier, C., Schlotterbeck, U., Antonietti, L., Zacharias, P., Thomann, R., Tiller, J. C. et al. (2002). Hybrids of silver nanoparticles with amphiphilic hyperbranched macromolecules exhibiting antimicrobial properties. Chemical Communications, 2002(24), 3018-3019.

Azizi Samir, M. A. S., Alloin, F., \& Dufresne, A. (2005). Review of recent research into cellulosic whiskers, their properties and their application in nanocomposite field. Biomacromolecules, 6, 612-626.
Azizi Samir, M. A. S., Alloin, F., Sanchez, J. Y., \& Dufresne, A. (2004). Cellulose nanocrystals reinforced poly(oxyethylene). Polymer, 45, 4149-4157.

Beall, G. W. (2000). New conceptual model for interpreting nanocomposite behavior. In T. J. Pinnavaia \& G. W. Beall (Eds.), Polymer-clay nanocomposites (pp. 267-279). New York: Wiley.

Bertini, F., Canetti, M., Audisio, G., Costa, G., \& Falqui, L. (2006). Characterization and thermal degradation of polypropylene-montmorillonite nanocomposites. Polymer Degradation and Stability, 91, 600-605.

Bharadwaj, R. K. (2001). Modeling the barrier properties of polymer-layered silicate nanocomposites. Macromolecules, 34, 9189-9192.

Bharadwaj, R. K., Mehrabi, A. R., Hamilton, C., Trujillo, C., Murga, M., Fan, R., Chavira, A., et al. (2002). Structure-property relationships in cross-linked polyester-clay nanocomposites. Polymer, 43(13), 3699-3705.

Bhatnagar, A., \& Sain, M. (2005). Processing of cellulose nanofiber-reinforced composites. Journal of Reinforced Plastics and Composites, 24(12), 1259-1268.

Bin, Y., Mine, M., Koganemaru, A., Jiang, X., \& Matsuo, M. (2006). Morphology and mechanical and electrical properties of oriented PVA-VGCF and PVA-MWNT composites. Polymer, 47, 1308-1317.

Boccuni, F., Rondinone, B., Petyx, C., \& Iavicoli, S. (2008). Potential occupationa exposure to manufactured nanoparticles in Italy. Journal of Cleaner Production, $16,949-956$

Bondeson, D., \& Oksman, K. (2007). Polylactic acid/cellulose whisker nanocomposites modified by polyvinyl alcohol. Composites: Part A, 38 2486-2492.

Bouwmeester, H., Dekkers, S., Noordam, M. Y., Hagens, W. I., Bulder, A. S., de Heer, C., et al. (2009). Review of health safety aspects of nanotechnologies in food production. Regulatory Toxicology and Pharmacology, 53(1), 52-62.

Brody, A. L. (2003). “Nano, nano” food packaging technology. Food Technology, $57(12), 52-54$

Brody, A. L. (2006). Nano and food packaging technologies converge. Food Technology, 60(3), 92-94

Brody, A. L. (2007). Nanocomposite technology in food packaging. Food Technology, 61(10), 80-83.

Brown, E. E., \& Laborie, M. P. G. (2007). Bioengineering bacterial cellulose/ poly(ethylene oxide) nanocomposites. Biomacromolecules, 8(10), 3074-3081.

Cabedo, L., Giménez, E., Lagaron, J. M., Gavara, R., \& Saura, J. J. (2004). Development of EVOH-kaolinite nanocomposites. Polymer, 45(15), 5233-5238.

Caseli, L., Santos, D. S., Jr., Foschini, M., Gonçalves, D., \& Oliveira, O. N. Jr., (2007) Control of catalytic activity of glucose oxidase in layer-by-layer films of chitosan and glucose oxidase. Materials Science and Engineering C, 27, $1108-1110$

Cava, D., Giménez, E., Gavara, R., \& Lagaron, J. M. (2006). Comparative performance and barrier properties of biodegradable thermoplastics and nanobiocomposites versus PET for food packaging applications. Journal of Plastic Film and Sheeting $22,265-274$

Chakraborty, A., Sain, M., \& Kortschot, M. (2006). Reinforcing potential of wood pulp-derived microfibres in a PVA matrix. Holzforschung, 60(1), 53-58.

Chawengkijwanich, C., \& Hayata, Y. (2008). Development of $\mathrm{TiO}_{2}$ powder-coated food packaging film and its ability to inactivate Escherichia coli in vitro and in actual tests. International Journal of Food Microbiology, 123(3), 288-292.

Chen, Y., Cao, X., Chang, P. R., \& Huneault, M. A. (2008). Comparative study on the films of poly(vinyl alcohol)/pea starch nanocrystals and poly(vinyl alcohol)/ native pea starch. Carbohydrate Polymers, 73, 8-17.

Chen, Y., Liu, C., Chang, P. R., Cao, X., \& Anderson, D. P. (2009). Bionanocomposites based on pea starch and cellulose nanowhiskers hydrolyzed from pea hull fibre: effect of hydrolysis time. Carbohydrate Polymers, 76(4), 607-615.

Chen, B., \& Evans, J. R. G. (2005). Thermoplastic starch-clay nanocomposites and their characteristics. Carbohydrate Polymers, 61, 455-463.

Chen, W., Tao, X., Xue, P., \& Cheng, X. (2005). Enhanced mechanical properties and morphological characterizations of poly(vinyl alcohol)-carbon nanotube composite films. Applied Surface Science, 252, 1404-1409.

Cheng, Q., Li, C., Pavlinek, V., Saha, P., \& Wang, H. (2006). Surface-modified antibacterial $\mathrm{TiO}_{2} / \mathrm{Ag}^{+}$nanoparticles: preparation and properties. Applied Surface Science, 252, 4154-4160.

Choi, W. Termin, A., \& Hoffmann, M. (1994). The role of metal ion dopants in quantum size $\mathrm{TiO}_{2}$ : correlation between photoreactivity and charge carrie recombination dynamics. The Journal of Physical Chemistry, 98, 13669-13679.

Cioffi, N., Torsi, L., Ditaranto, N., Tantillo, G., Ghibelli, L., Sabbatini, L., et al. (2005). Copper nanoparticle/polymer composites with antifungal and bacteriostatic properties. Chemistry of Materials, 17, 5255-5262.

Collister, J. (2002). Commercialisation of polymer nanocomposites. In R. Krishnamoorti \& R. A. Vaia (Eds.), Polymer nanocomposites: Synthesis, characterisation and modelling. Washington: American Chemical Society.

Cyras, V. P., Manfredi, L. B., Ton-That, M. T., \& Vázquez, A. (2008). Physical and mechanical properties of thermoplastic starch/montmorillonite nanocomposite films. Carbohydrate Polymers, 73, 55-63.

Dalmas, F., Cavaillé, J. Y., Gauthier, C., Chazeau, L., \& Dendievel, R. (2007) Viscoelastic behavior and electrical properties of flexible nanofiber filled polymer nanocomposites. Influence of processing conditions. Composites Science and Technology, 67, 829-839.

Damm, C., Münstedt, H., \& Rösch, A. (2007). Long-term antimicrobial polyamide 6 silver-nanocomposites. Journal of Materials Science, 42(15), 6067-6073.

Damm, C., Münstedt, H., \& Rösch, A. (2008). The antimicrobial efficacy of polyamide 6/silver-nano- and microcomposites. Materials Chemistry and Physics, 108, 61-66. 
Dammström, S., Salmén, L., \& Gatenholm, P. (2005). The effect of moisture on the dynamical mechanical properties of bacterial cellulose/glucuronoxylan nanocomposites. Polymer, 46(23), 10364-10371.

De Moura, M. R., Aouada, F. A., Avena-Bustillos, R. J., McHugh, T. H., Krochta, J. M., \& Mattoso, L. H. C. (2009). Improved barrier and mechanical properties of novel hydroxypropyl methylcellulose edible films with chitosan/tripolyphosphate nanoparticlses. Journal of Food Engineering, 92, 448-453.

Dean, K., Yu, L., \& Wu, D. Y. (2007). Preparation and characterization of meltextruded thermoplastic starch/clay nanocomposites. Composites Science and Technology, 67, 413-421.

Dogan, N., \& McHugh, T. H. (2007). Effects of microcrystalline cellulose on functional properties of hydroxyl propyl methyl cellulose microcomposite films. Journal of Food Science, 72(1), E16-E22.

Dubief, D., Samain, E., \& Dufresne, A. (1999). Polysaccharide microcrystals reinforced amorphous poly( $\beta$-hydroxyoctanoate) nanocomposite materials. Macromolecules, 32(18), 5765-5771.

Dufresne, A., Dupeyre, D., \& Vignon, M. R. (2000). Cellulose microfibrils from potato tuber cells: processing and characterization of starch-cellulose microfibril composites. Journal of Applied Polymer Science, 76(14), 2080-2092.

Dufresne, A., \& Vignon, M. R. (1998). Improvement of starch film performances using cellulose microfibrils. Macromolecules, 31, 2693-2696.

Dujardin, E., Blaseby, M., \& Mann, S. (2003). Synthesis of mesoporous silica by solgel mineralisation of cellulose nanorod nematic suspensions. Journal of Materials Chemistry, 13(4), 696-699.

Fernández, A., Cava, D., Ocio, M. J., \& Lagaron, J. M. (2008). Perspectives for biocatalysts in food packaging. Trends in Food Science \& Technology, 19(4), 198-206.

Föster, S., \& Konrad, M. (2003). From self-organising polymers to nano- and biomaterials. Journal of Materials Chemistry, 13, 2671-2688.

Freire, C. S. R., Silvestre, A. J. D., Pascoal Neto, C., Gandini, A., Martin, L., \& Mondragon, I. (2008). Composites based on acylated cellulose fibers and lowdensity polyethylene: effect of the fiber content, degree of substitution and fatty acid chain length on final properties. Composites Science and Technology, 68(15-16), 3358-3364.

Fujishima, A., Rao, T. N., \& Tryk, D. A. (2000). Titanium dioxide photocatalysis Journal of Photochemistry and Photobiology C: Photochemistry Reviews, 1(1), 1-21.

Galdikas, A., Mironas, A., Senulienè, V., Šetkus, A., \& Zelenin, D. (2000). Response time based output of metal oxide gas sensors applied to evaluation of meat freshness with neural signal analysis. Sensors and Actuators B, 69, 258265.

Gardner, D. J., Oporto, G. S., Mills, R., \& Azizi Samir, M. A. S. (2008). Adhesion and surface issues in cellulose and nanocellulose. Journal of Adhesion Science and Technology, 22, 545-567.

Gelover, S., Gómez, L. A., Reyes, K., \& Leal, M. T. (2006). A practical demonstration of water disinfection using $\mathrm{TiO}_{2}$ films and sunlight. Water Research, 40, 3274-3280.

Gopinath, S., \& Sugunan, S. (2007). Enzymes immobilized on montmorillonite K 10 : effect of adsorption and grafting on the surface properties and the enzyme activity. Applied Clay Science, 35(1-2), 67-75.

Gu, H. W., Ho, P. L., Tong, E., Wang, L., \& Xu, B. (2003). Presenting vancomycin on nanoparticles to enhance antimicrobial activities. Nano Letters, 3, 1261-1263.

Gutiérrez-Tauste, D., Domènech, X., Casañ-Pastor, N., \& Ayllón, J. A. (2007) Characterization of methylene blue $/ \mathrm{TiO}_{2}$ hybrid thin films prepared by the liquid phase deposition (LPD) method: application for fabrication of lightactivated colorimetric oxygen indicators. Journal of Photochemistry and Photobiology A: Chemistry, 187, 45-52.

Haynie, D. T., Zhang, L., Zhao, W., \& Rudra, J. S. (2006). Protein-inspired multilayer nanofilms: science, technology and medicine. Nanomedicine: Nanotechnology, Biology, and Medicine, 2, 150-157.

Helbert, W., Cavaillé, C. Y., \& Dufresne, A. (1996). Thermoplastic nanocomposites filled with wheat straw cellulose whiskers. Part I: processing and mechanica behaviour. Polymer Composites, 17(4), 604-611.

Helbert, W., \& Chanzy, H. (1994). Oriented growth of V amylase n-butanol crystals on cellulose. Carbohydrate Polymers, 24, 119-122.

Hu, A. W., \& Fu, Z. H. (2003). Nanotechnology and its application in packaging and packaging machinery. Packaging Engineering, 24, 22-24.

Huang, L., Li, D. Q., Lin, Y. J., Wei, M., Evans, D. G., \& Duan, X. (2005). Controllable preparation of nano-MgO and investigation of its bactericidal properties. Journal of Inorganic Biochemistry, 99, 986-993.

Huang, Z. M., Zhang, Y., Kotaki, M., \& Ramakrishna, S. (2003). A review on polymer nanofibers by electrospinning and their applications in nanocomposites. Composites Sciences and Technology, 63(15), 2223-2253.

Hubbe, M. A., Rojas, O. J., Lucia, L. A., \& Sain, M. (2008). Cellulosic nanocomposites: a review. Bioresources, 3(3), 929-980.

Hulleman, S. H. D., Helbert, W., \& Chanzy, H. (1996). Single crystals of V amylose complexed with glycerol. International Journal of Biological Macromolecules, 18 $115-122$.

Iwatake, A., Nogi, M., \& Yano, H. (2008). Cellulose nanofiber-reinforced polylactic acid. Composites Science and Technology, 68, 2103-2106.

Jang, W. S., Rawson, I., \& Grunlan, J. C. (2008). Layer-by-layer assembly of thin film oxygen barrier. Thin Solid Films, 516(15), 4819-4825.

Jawahar, P., \& Balasubramanian, M. (2006). Preparation and properties of polyesterbased nanocomposite gel coat system. Journal of Nanomaterials, 4 [article ID 21656].

Jia, X., Li, Y., Cheng, Q., Zhang, S., \& Zhang, B. (2007). Preparation and properties of poly(vinyl alcohol)/silica nanocomposites derived from copolymerization of vinyl silica nanoparticles and vinyl acetate. European Polymer Journal, 43, 1123-1131.

Jia, H. F., Zhu, G. Y., Vugrinovich, B., Kataphinan, W., Reneker, D. H., \& Wang, P. (2002). Enzyme-carrying polymeric nanofibers prepared via electrospinning for use as unique biocatalysts. Biotechnology Progress, 18(5), 1027-1032.

Jiang, B., Liu, C., Zhang, C., Wang, B., \& Wang, Z. (2007). The effect of non-symmetric distribution of fiber orientation and aspect ratio on elastic properties of composites. Composites: Part B, 38, 24-34.

Johnston, J. H., Borrmann, T., Rankin, D., Cairns, M., Grindrod, J. E., \& McFarlane, A (2008). Nano-structured composite calcium silicate and some novel applications. Current Applied Physics, 8(3-4), 504-507.

Jordan, J., Jacob, K. I., Tannenbaum, R., Sharaf, M. A., \& Jasiuk, I. (2005). Experimental trends in polymer nanocomposites: a review. Materials Science \& Engineering A, $393(1-2), 1-11$.

Joseph, T., \& Morrison, M. (2006). Nanotechnology in agriculture and food. <http:// www.nanoforum.org/nf06 modul showmore folder 99999 scid 377 .html? action=longview_publication>.

Kahn, J. (2006). Nano's big future - tiny technology promises big rewards. Some may already be in your closet. National Geographic, 209, 98-119.

Kandimalla, V. B., Tripathi, V. S., \& Ju, H. (2006). Immobilization of biomolecules in sol-gels: biological and analytical applications. Critical Reviews in Analytical Chemistry, 36(2), 73-106.

Kang, S., Pinault, M., Pfefferle, L. D., \& Elimelech, M. (2007). Single-walled carbon nanotubes exhibit strong antimicrobial activity. Langmuir, 23, 8670-8673.

Kapoor, S., Lawless, D., Kennepohl, P., Meisel, D., \& Serpone, N. (1994). Reduction and aggregation of silver ions in aqueous gelatin solutions. Langmuir, 10(9), 3018-3022.

Khademhosseini, A., \& Langer, R. (2006). Nanobiotechnology: drug delivery and tissue engineering. Chemical Engineering Progress, 102(2), 38-42.

Kim, J. Y., Han, S., II, \& Hong, S. (2008). Effect of modified carbon nanotube on the properties of aromatic polyester nanocomposites. Polymer, 49, 3335-3345.

Kim, Y., Jung, R., Kim, H. S., \& Jin, H. J. (2009). Transparent nanocomposites prepared by incorporating microbial nanofibrils into poly(L-lactic acid). Current Applied Physics, 9(1), S69-S71.

Kim, B., Kim, D., Cho, D., \& Cho, S. (2003). Bactericidal effect of $\mathrm{TiO}_{2}$ photocatalyst on selected food-borne pathogenic bacteria. Chemosphere, 52(1), 277-281.

Kim, T. Y., Lee, Y. H., Park, K. H., Kim, S. J., \& Cho, S. Y. (2005). A study of photocatalysis of $\mathrm{TiO}_{2}$ coated onto chitosan beads and activated carbon. Research on Chemical Intermediates, 31(4-6), 343-358.

Kim, K. Y., Lim, H. J., Park, S. M., \& Lee, S. J. (2003). Synthesis and characterization of high impact polystyrene/organically modified layered silicate nanocomposites. Polymer (Korea), 27(4), 377-384.

Koh, H. C., Park, J. S., Jeong, M. A., Hwang, H. Y., Hong, Y. T., Ha, S. Y., et al. (2008). Preparation and gas permeation properties of biodegradable polymer/layered silicate nanocomposite membranes. Desalination, 233, 201-209.

Kristo, E., \& Biliaderis, C. G. (2007). Physical properites of starch nanocrystalreinforced pullulan films. Carbohydrate Polymers, 68, 146-158.

Kumar, R., \& Münstedt, H. (2005). Silver ion release from antimicrobial polyamide/ silver composites. Biomaterials, 26, 2081-2088.

Kvien, I., \& Oksman, K. (2007). Orientation of cellulose nanowhiskers in polyvinyl alcohol. Applied Physics A: Materials Science and Processing, 87, 641-643.

Kvítek, L., Panácek, A., Soukupová, J., Kolář, M., Veceřová, R., Prucek, R., et al. (2008). Effect of surfactants and polymers on stability and antibacterial activity of silver nanoparticles (NPs). The Journal of Physical Chemistry C, 112(15), 5825-5834.

Lagaron, J. M., Cabedo, L., Cava, D., Feijoo, J. L., Gavara, R., \& Gimenez, E. (2005). Improving packaged food quality and safety part 2: nanocomposites. Food Additives and Contaminants, 22(100), 994-998.

Lagaron, J. M., Catalá, R., \& Gavara, R. (2004). Structural characteristics defining high barrier polymeric materials. Materials Science and Technology, 20, 1-7.

Lau, K. T., \& Hui, D. (2002). The revolutionary creation of new advanced Materials carbon nanotube composites. Composites Part B, 33(4), 263-277.

Lee, S. K., Sheridan, M., \& Mills, A. (2005). Novel UV-activated colorimetric oxygen indicator. Chemistry of Materials, 17(10), 2744-2751.

Li, H., Li, F., Wang, L., Sheng, J., Xin, Z., Zhao, L., et al. (2009). Effect of nano-packing on preservation quality of Chinese jujube (Ziziphus jujuba Mill. var. inermis (Bunge) Rehd). Food Chemistry, 114(2), 547-552.

Li, Q., Mahendra, S., Lyon, D. Y., Brunet, L., Liga, M. V., Li, D., \& Alvarez, P. J. J. (2008). Antimicrobial nanomaterials for water disinfection and microbial control: potential applications and implications. Water Research, 42(18), 4591-4602.

Li, B., Rozas, J., \& Haynie, D. T. (2006). Structural stability of polypeptide nanofilms under extreme conditions. Biotechnology Progress, 22, 111-117.

Liao, F., Chen, C., \& Subramanian, V. (2005). Organic TFTs as gas sensors for electronic nose applications. Sensors and Actuators B: Chemical, 107(2), 849-855.

Liau, S. Y., Read, D. C., Pugh, W. J., Furr, J. R., \& Russell, A. D. (1997). Interaction of silver nitrate with readily identifiable groups: relationship to the antibacterial action of silver ions. Letters in Applied Microbiology, 25, 279-283.

Lima, M. M. D., \& Borsali, R. (2004). Rodlike cellulose microcrystals: structure, properties, and applications. Macromolecular Rapid Communications, 25(7), 771-787.

Lin, Y. J., Li, D. Q., Wang, G., Huang, L., \& Duan, X. (2005). Preparation and bactericidal property of $\mathrm{MgO}$ nanoparticles on $\gamma-\mathrm{Al}_{2} \mathrm{O}_{3}$. Journal of Materials Science: Materials in Medicine, 16, 53-56.

Ljungberg, N., Bonini, C., Bortolussi, F., Boisson, C., Heux, L., \& Cavaillé, J. Y. (2005). New nanocomposite materials reinforced with cellulose whiskers in atactic popypropylene: effect of surface and dispersion characteristics. Biomacromolecules, 6(5), 2732-2739. 
López Manchado, M. A., Valentini, L., Biagotti, J., \& Kenny, J. M. (2005). Thermal and mechanical properties of single-walled carbon nanotubes-polypropylene composites prepared by melt processing. Carbon, 43, 1499-1505.

López-León, T., Carvalho, E. L. S., Seijo, B., Ortega-Vinuesa, J. L., \& Bastos-González, D. (2005). Physicochemical characterization of chitosan nanoparticles: electrokinetic and stability behavior. Journal of Colloid Interface Science, 283, 344-351.

Lopez-Rubio, A., Gavara, R., \& Lagaron, J. M. (2006). Bioactive packaging: turning foods into healthier foods through biomaterials. Trends in Food Science $\mathcal{E}$ Technology, 17, 567-575.

Lotti, C., Isaac, C. S., Branciforti, M. C., Alves, R. M. V., Liberman, S., \& Bretas, R. E. S. (2008). Rheological, mechanical and transport properties of blown films of high density polyethylene nanocomposites. European Polymer Journal, 44, 1346-1357.

Lu, Y., Weng, L., \& Cao, X. (2005). Biocomposites of plasticizes starch reinforced with cellulose crystallites from cottonseed linter. Macromolecular Bioscience, 5 1101-1107.

Lu, Y., Weng, L., \& Zhang, L. (2004). Morphology and properties of soy protein isolate thermoplastics reinforced with chitin whiskers. Biomacromolecules, 5, 1046-1051.

Ludueña, L. N., Alvarez, V. A., \& Vasquez, A. (2007). Processing and microstructure of PCL/clay nanocomposites. Materials Science and Engineering: A, 121-129.

Luo, P. G., \& Stutzenberger, F. J. (2008). Nanotechnology in the detection and control of microorganisms. In A. I. Laskin, S. Sariaslani, \& G. M. Gadd (Eds.). Advances in Applied Microbiology (Vol. 63, pp. 145-181). London: Elsevier.

Maness, P. C., Smolinski, S., Blake, D. M., Huang, Z., Wolfrum, E. J., \& Jacoby, W. A (1999). Bactericidal activity of photocatalytic $\mathrm{TiO}_{2}$ reaction: toward an understanding of its killing mechanism. Applied and Environmental Microbiology, 65(9), 4094-4098.

Mangiacapra, P., Gorrasi, G., Sorrentino, A., \& Vittoria, V. (2006). Biodegradable nanocomposites obtained by ball milling of pectin and montmorillonites. Carbohydrate Polymers, 64, 516-523.

Markarian, J. (2005). Automotive and packaging offer growth opportunities for nanocomposites. Plastics, Additives and Compounding, 7(6), 18-21.

Marras, S. I., Kladi, K. P., Tsivintzelis, I., Zuburtikudis, I., \& Panayiotou, C. (2008). Biodegradable polymer nanocomposites: the role of nanoclays on the thermomechanical characteristics and the electrospun fibrous structure. Acta Biomaterialia, 4(3), 756-765.

Mathew, A. P., \& Dufresne, A. (2002). Morphological investigation of nanocomposites from sorbitol plasticized starch and tunicin whiskers. Biomacromolecules, 3(3), 609-617.

Mbhele, Z. H., Salemane, M. G., van Sittert, C. G. C. E., Nedeljkovíc, J. M., Djokovíc, V., \& Luyt, A. S. (2003). Fabrication and characterization of silver-polyvinyl alcohol nanocomposites. Chemistry of Materials, 15(26), 5019-5024.

Mills, A., \& Hazafy, D. (2009). Nanocrystalline $\mathrm{SnO}_{2}$-based, UVB-activated, colourimetric oxygen indicator. Sensor and Actuators B: Chemical, 136(2), 344-349.

Mills, A., Doyle, G., Peiro, A. M., \& Durrant, J. (2006). Demonstration of a novel, flexible, photocatalytic oxygen-scavenging polymer film. Journal of Photochemistry and Photobiology A: Chemistry, 177, 328-331.

Mirzadeh, A., \& Kokabi, M. (2007). The effect of composition and draw-down ratio on morphology and oxygen permeability of polypropylene nanocomposite blown films. European Polymer Journal, 43(9), 3757-3765.

Mohanty, A. K., Misra, M., \& Drzal, L. T. (2001). Surface modifications of natural fibers and performance of the resulting biocomposites: an overview. Composite Interfaces, 8(5), 313-343.

Mokoena, M. A., Djoković, V., \& Luyt, A. S. (2004). Composites of linear low density polyethylene and short sisal fibres: the effects of peroxide treatment. Journal of Materials Science, 39, 3403-3412.

Monteiro-Riviere, N. A., Nemanich, R. J., Inman, A. O., Wang, Y. Y., \& Riviere, J. E. (2005). Multi-walled carbon nanotube interactions with human epidermal keratinocytes. Toxicology Letters, 155(13), 377-384.

Moraru, C. I., Panchapakesan, C. P., Huang, Q., Takhistov, P., Liu, S., \& Kokini, J. L. (2003). Nanotechnology: a new frontier in Food Science. Food Technology, 57, 24-29.

Morones, J. R., Elechiguerra, J. L., Camacho, A., Holt, K., Kouri, J. B., Ramirez, J. T., et al. (2005). The bactericidal effect of silver nanoparticles. Nanotechnology, 16(10), $2346-2353$

Nachay, K. (2007). Analyzing nanotechnology. Food Technology, 61(1), 34-36.

Nakagaito, A. N., Iwamoto, S., \& Yano, H. (2005). Bacterial cellulose: the ultimate nano-scalar cellulose morphology for the production of high-strength composites. Applied Physics A: Materials Science E Processing 80(1), 93-97.

Nielsen, L. E. (1967). Models for the permeability of filled polymer systems. Journal of Macromolecular Science, Part A: Pure and Applied Chemistry, 1(5), 929-942.

Nishino, T., Matsuda, I., \& Hirao, K. (2004). All-cellulose composite. Macromolecules, 37, 7683-7687.

Oksman, K., Mathew, A. P., Bondeson, D., \& Kvien, I. (2006). Manufacturing process of cellulose whiskers/polylactic acid nanocomposites. Composites Science and Technology, 66(15), 2776-2784.

Osman, M. A., Ploetze, M., \& Suter, U. W. (2003). Surface treatment of clay minerals - thermal stability, basal-plane spacing and surface coverage. Journal of Materials Science, 13, 2359-2366.

Osman, M. A., Rupp, J. E. P., \& Suter, U. W. (2005). Effect of non-ionic surfactants on the exfoliation and properties of polyethylene-layered silicate nanocomposites. Polymer, 46, 8202-8209.
Page, K., Palgrave, R. G., Parkin, I. P., Wilson, M., Savin, S. L. P., \& Chadwick, A. V. 2007). Titania and silver-titania composite films on glass-potent antimicrobial coatings. Journal of Materials Chemistry, 17(1), 95-104.

Paiva, L. B., Morales, A. R., \& Díaz, F. R. V. (2008). Organoclays: properties, preparation and applications. Applied Clay Science, 42, 8-24.

Paralikar, S. A., Simonsen, J., \& Lombardi, J. (2008). Poly(vinyl alcohol)/cellulose nanocrystal barrier membranes. Journal of Membrane Science, 320(1-2) 248-258.

Park, H. M., Lee, W. K., Park, C. Y., Cho, W. J., \& Ha, C. S. (2003). Environmentally friendly polymer hybrids: part I. Mechanical, thermal, and barrier properties of the thermoplastic starch/clay nanocomposites. Journal of Materials Science, 38 , 909-915.

Park, H. M., Liang, X., Mohanty, A. K., Misra, M., \& Drzal, L. T. (2004). Effect of compatibilizer on nanostructure of the biodegradable cellulose acetate/ organoclay nanocomposites. Macromolecules, 37, 9076-9082.

Paul, M. A., Alexandre, M., Degée, P., Henrist, C., Rulmont, A., \& Dubois, P. (2003) New nanocomposite materials based on plasticized poly(L-lactide) and organomodified montmorillonites: thermal and morphological study. Polymer, 44(2), $443-450$.

Petersson, L., Kvien, I., \& Oksman, K. (2007). Structure and thermal properties of poly(lactic acid)/cellulose whiskers nanocomposite materials. Composites Science and Technology, 67, 2535-2544.

Petersson, L., \& Oksman, K. (2006a). Biopolymer based nanocomposites: comparing layered silicates and microcrystalline cellulose as nanoreinforcement Composites Science and Technology, 66, 2187-2196.

Petersson, L., \& Oksman, K. (2006b). Preparation and properties of biopolymer based nanocomposite films using microcrystalline cellulose. In K. Oksman \& M. Sain (Eds.), Cellulose nanocomposites, processing, characterization and properties. ACS symposium series 938 (pp. 132-150). Oxford: Oxford University Press.

Picard, E., Gauthier, H., Gérard, J. F., \& Espuche, E. (2007). Influence of the intercalated cations on the surface energy of montmorillonites: consequences for the morphology and gas barrier properties of polyethylene/ montmorillonites nanocomposites. Journal of Colloid and Interface Science, 307. 364-376.

Podsiadlo, P., Choi, S. Y., Shim, B., Lee, J., Cuddihy, M., \& Kotov, N. A. (2005) Molecularly engineered nanocomposites: layer-by-layer assembly of cellulose nanocrystals. Biomacromolecules, 6, 2914-2918.

Prashantha, K., Soulestin, J., Lacrampe, M. F., Krawczak, P., Dupin, G., \& Claes, M. (in press). Masterbatch-based multi-walled carbon nanotube filled polypropylene nanocomposites: assessment of rheological and mechanical properties. Composites Science and Technology.

Qhobosheane, M., Santra, S., Zhang, P., \& Tan, W. H. (2001). Biochemically functionalized silica nanoparticles. Analyst, 126(8), 1274-1278.

Qi, L. F., Xu, Z. R., Jiang, X., Hu, C., \& Zou, X. (2004). Preparation and antibacterial activity of chitosan nanoparticles. Carbohydrate Research, 339, 2693-2700.

Qiao, R., \& Brinson, L. C. (2009). Simulation of interphase percolation and gradients in polymer nanocomposites. Composites Science and Technology, 69(3-4) 491-499.

Rabea, E. I., Badawy, M. E., Stevens, C. V., Smagghe, G., \& Steurbaut, W. (2003) Chitosan as antimicrobial agent: applications and mode of action. Biomacromolecules, 4(6), 1457-1465.

Rajesh Takashima, W., \& Kaneto, K. (2004). Amperometric phenol biosensor based on covalent immobilization of tyrosinase onto an electrochemically prepared novel copolymer poly(N-3-aminopropyl pyrrole-copolymer) film. Sensors and Actuators B, 102, 271-277.

Ramos, L. P. (2003). The chemistry involved in the stream treatment of lignocellulosic materials. Química Nova, 26(6), 863-871.

Ray, S., Easteal, A., Quek, S. Y., \& Chen, X. D. (2006). The potential use of polymerclay nanocomposites in food packaging. International Journal of Food Engineering, 2(4). art. 5.

Reddy, M. P., Venugopal, A., \& Subrahmanyam, M. (2007). Hydroxyapatitesupported $\mathrm{Ag}-\mathrm{TiO}_{2}$ as Escherichia coli disinfection photocatalyst. Water Research, 41, 379-386.

Ren, G. L., Xu, X. H., Liu, Q., Cheng, J., Yuan, X. Y., Wu, L. L., \& Wan, Y. (2006) Electrospun poly(vinyl alcohol)/glucose oxidase biocomposite membranes for biosensor applications. Reactive \& Functional Polymers, 66(12), 1559-1564.

Retama, R. J. (2005). Synthesis and characterization of semiconducting polypyrrole/ polyacrylamide microparticles with GOx for biosensor applications. Colloids and Surfaces A: Physicochemical and Engineering Aspects, 239-244.

Rhim, J. W., \& Ng, P. K. W. (2007). Natural biopolymer-based nanocomposite films for packaging applications. Critical Reviews in Food Science and Nutrition, 47(4) 411-433.

Robertson, J. M. C., Robertson, P. K. J., \& Lawton, L. A. (2005). A comparison of the effectiveness of $\mathrm{TiO}_{2}$ photocatalysis and UVA photolysis for the destruction of three pathogenic micro-organisms. Journal of Photochemistry and Photobiology A: Chemistry, 175(1), 51-56.

Roco, M. C. (2003). Nanotechnology: convergence with modern biology and medicine. Current Opinion in Biotechnology, 14(3), 337-346.

Rudra, J. S., Dave, K., \& Haynie, D. T. (2006). Antimicrobial polypeptide multilayer nanocoatings. Journal of Biomaterials Science - Polymer Edition, 17(11) $1301-1315$.

Ruhr, E., \& Sahl, H. G. (1985). Mode of action of the peptide antibiotic nisin and influence on the membrane potential of whole cells and on cytoplasmic and artificial membrane vesicles. Antimicrobial Agents and Chemotherapy, 27 841-845. 
Russo, G. M., Nicolais, V., Di Maio, L., Montesano, S., \& Incarnato, L. (2007) Rheological and mechanical properties of nylon 6 nanocomposites submitted to reprocessing with single and twin-screw extruders. Polymer Degradation and Stability, 92(10), 1925-1933.

Sahl, H. G., Kordel, M., \& Benz, R. (1987). Voltage-dependent depolarization of bacterial membranes and artificial lipid bilayers by the peptide antibiotic nisin. Archives of Microbiology, 149, 120-124.

Sanchez-Garcia, M. D., Gimenez, E., \& Lagaron, J. M. (2008). Morphology and barrier properties of solvent cast composites of thermoplastic biopolymers and purified cellulose fibers. Carbohydrate Polymers, 71, 235-244.

Sanguansri, P., \& Augustin, M. A. (2006). Nanoscale materials development - a food industry perspective. Trends in Food Science \& Technology, 17(10), 547-556.

Šetkus, A. (2002). Heterogeneous reaction rate based description of the response kinetics in metal oxide gas sensors. Sensors and Actuators B, 87, 346-357.

Sharma, A. L., Singhal, R., Kumar, A., Rajesh Pande, K. K., \& Malhotra, B. D. (2004) Immobilization of glucose oxidase onto electrochemically prepared poly(aniline-co-fluoroaniline) films. Journal of Applied Polymer Science, 91(6), 3999-4006.

Sharma, V. K., Yngard, R. A., \& Lin, Y. (2009). Silver nanoparticles: green synthesis and their antimicrobial activities. Advances in Colloid and Interface Science, 145, 83-96.

Shvedova, A., Castranova, V., Kisin, E., Schwegler-Berry, D., Murray, A., Gandelsman, V., et al. (2003). Exposure to carbon nanotube material: assessment of nanotube cytotoxicity using human keratinocyte cells. Journal of Toxicology and Environmental Health, Part A, 66(20), 1909-1926.

Sinegani, A. A. S., Emzitai, G., \& Shariamadari, H. (2005). Sorption and immobilization of cellulase on silicate clay minerals. Journal of Colloid Interface Science, 290, 39-44.

Soares, N. F. F., \& Hotchkiss, J. H. (1998). Naringinase immobilization in packaging films for reducing naringin concentration in grapefruit juice. Journal of Food Science, 63, 61-65.

Son, W. K., Youk, J. H., \& Park, W. H. (2006). Antimicrobial cellulose acetate nanofibers containing silver nanoparticles. Carbohydrate Polymers, 65, 430434.

Sondi, I., \& Salopek-Sondi, B. (2004). Silver nanoparticles as antimicrobial agent: a case study on E. coli as a model for Gram-negative bacteria. Journal of Colloid Interface Science, 275, 177-182.

Sorrentino, A., Gorrasi, G., \& Vittoria, V. (2007). Potential perspectives of bionanocomposites for food packaging applications. Trends in Food Science $\mathcal{E}$ Technology, 18(2), 84-95.

Sriupayo, J., Supaphol, P., Blackwell, J., \& Rujiravanit, R. (2005). Preparation and characterization of $\alpha$-chitin whisker-reinforced chitosan nanocomposite films with or without heat treatment. Carbohydrate Polymers, 62, 130-136.

Stoimenov, P., Klinger, R. L., Marchin, G. L., \& Klabunde, K. J. (2002). Metal oxide nanoparticles as bactericidal agents. Langmuir, 18, 6679-6686.

Sun, D. P., Zhou, L. L., Wu, Q. H., \& Yang, S. L. (2007). Preliminary research on structure and properties of nano-cellulose. Journal of Wuhan University of Technology - Materials Science Edition, 22(4), 677-680.

Svagan, A. J., Hedenqvist, M. S., \& Berglund, L. (2009). Reduced water vapour sorption in cellulose nanocomposites with starch matrix. Composites Science and Technology, 69(3-4), 500-506.

Tan, W., Zhang, Y., Szeto, Y. S., \& Liao, L. (2008). A novel method to prepare chitosan/ montmorillonite nanocomposites in the presence of hydroxyl-aluminum olygomeric cations. Composites Science and Technology, 68(14), 2917-2921.

Tang, C., \& Liu, H. (2008). Cellulose nanofiber reinforced poly(vinyl alcohol) composite film with high visible light transmittance. Composites Part A Applied Science and Manufacturing, 39(10), 1638-1643.

Tang, S., Zou, P., Xiong, H., \& Tang, H. (2008). Effect of nano-SiO ${ }_{2}$ on the performance of starch/polyvinyl alcohol blend films. Carbohydrate Polymers, 72, 521-526.

Tankhiwale, R., \& Bajpai, S. K. (2009). Graft co-polymerization onto cellulose-based filter paper and its further development as silver nanoparticles-loaded antibacterial food packaging material. Colloids and Surfaces, 69(2), 164-168.
Tharanathan, R. N. (2003). Biodegradable films and composite coatings: past, present and future. Trends in Food Science E Technology, 14(3), 71-78.

Uyama, H., Kuwabara, M., Tsujimoto, T., Nakano, M., Usuki, A., \& Kobayashi, S. (2003). Green nanocomposite from renewable resources: plant oil-clay hybrid materials. Chemistry of Materials, 15, 2492-2494.

Vaidya, U. R., \& Bhattacharya, M. (1994). Properties of blends of starch and synthetic polymers containing anhydride groups. Journal of Applied Polymer Science, 52(5), 617-628.

Vladimiriov, V., Betchev, C., Vassiliou, A., Papageorgiou, G., \& Bikiaris, D. (2006). Dynamic mechanical and morphological studies of isotactic polypropylene/ fumed silica nanocomposites with enhanced gas barrier properties. Composites Science and Technology, 66, 2935-2944.

Wang, B., \& Sain, M. (2007). Isolation of nanofibers from soybean source and their reinforcing capability on synthetic polymers. Composites Science and Technology, 67(11-12), 2521-2527.

Warheit, D. B., Laurence, B. R., Reed, K. L., Roach, D. H., Reynolds, G. A. M., \& Webb, T R. (2004). Comparative pulmonary toxicity assessment of single-wall carbon nanotubes in rats. Toxicological Sciences, 77, 117-125.

Weiss, J., Takhistov, P., \& McClements, D. J. (2006). Functional materials in food nanotechnology. Journal of Food Science, 71(9), R107-R116.

Wiley, B., Sun, Y., Mayers, B., \& Xia, Y. (2005). Shape-controlled synthesis of metal nanostructures: the case of silver. Chemistry - A European Journal, 11(2), 454-463.

Wong, J. E., Rehfeldt, F., Hanni, P., Tanaka, M., \& Klitzing, R. V. (2004). Swelling behavior of polyelectrolyte multilayers in saturated water vapor. Macromolecules, 37(19), 7285-7289.

Wu, Q., Henriksson, M., Liu, X., \& Berglund, L. A. (2007). A high strength nanocomposite based on microcrystalline cellulose and polyurethane. Biomacromolecules, 8, 3687-3692.

Wu, L., Yuan, X., \& Sheng, J. (2005). Immobilization of cellulase in nanofibrous PVA membranes by electrospinning. Journal of Membrane Science, 250(1-2), $167-173$.

Wu, C. L., Zhang, M. Q., Rong, M. Z., \& Friedrick, K. (2002). Tensile performance improvement of low nanoparticles filled-polypropylene composites. Composites Science and Technology, 62, 1327-1340.

Xiao-e, L., Green, A. N. M., Haque, S. A., Mills, A., \& Durrant, J. R. (2004). Light-driven oxygen scavenging by titania/polymer nanocomposite films. Journal of Photochemistry and Photobiology A: Chemistry, 162, 253-259.

Xiong, H. G., Tang, S. W., Tang, H. L., \& Zou, P. (2008). The structure and properties of a starch-based biodegradable film. Carbohydrate Polymers, 71, 263-268.

Xu, Y., Ren, X., \& Hanna, M. A. (2006). Chitosan/clay nanocomposite film preparation and characterization. Journal of Applied Polymer Science, 99(4), 1684-1691.

Yano, S., Maeda, H., Nakajima, M., Hagiwara, T., \& Sawaguchi, T. (2008). Preparation and mechanical properties of bacterial cellulose nanocomposites loaded with silica nanoparticles. Cellulose, 15(1), 111-120.

Yu, Y. H., Lin, C. Y., Yeh, J. M., \& Lin, W. H. (2003). Preparation and properties of poly(vinyl alcohol)-clay nanocomposite materials. Polymer, 44(12), 3553-3560.

Yu, H., Xu, X., Chen, X., Lu, T., Zhang, P., \& Jing, X. (2007). Preparation and antibacterial effects of PVA-PVP hydrogels containing silver nanoparticles. Journal of Applied Polymer Science, 103, 125-133.

Zeng, H., Gao, C., Wang, Y., Watts, P. C. P., Kong, H., Cui, X., et al. (2006). In situ polymerization approach to multiwalled carbon nanotubes-reinforced nylon 1010 composites: mechanical properties and crystallization behavior. Polymer, 47, 113-122.

Zhang, M. Q., \& Rong, M. Z. (2003). Performance improvement of polymers by the addition of grafted nano-inorganic particles. Chinese Journal of Polymer Science, 21(6), 587-602.

Zhou, X., Shin, E., Wang, K. W., \& Bakis, C. E. (2004). Interfacial damping characteristics of carbon nanotube-based composites. Composites Science and Technology, 64(15), 2425-2437.

Zimmermann, T., Pöhler, E., \& Geiger, T. (2004). Cellulose fibrils for polymer reinforcement. Advanced Engineering Materials, 6(9), 754-761. 